Supplementary Information

\title{
Spatial Bias in Antibody Microarrays may be an Underappreciated Source of Variability
}

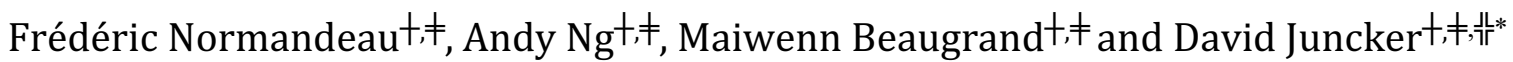

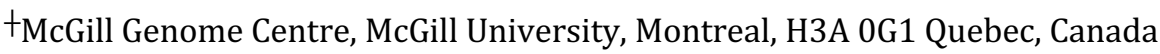 \\ ₹Department of Biomedical Engineering, McGill University, Montreal, H3A 2B4 Quebec, Canada \\ 帖Department of Neurology and Neurosurgery, McGill University, Montreal, H3A 2B4 Quebec, Canada
}

\begin{abstract}
ABBREVIATIONS
1,3-But, 1,3-butanediol; 2,3-But, 2,3-butanediol; AF488, Alexa Fluor 488; AF546, Alexa Fluor 546; AF647, Alexa Fluor 647; CAG, chicken-anti-goat; CV, coefficient of variation; DAG, donkey anti-goat; DMSO, dimethyl sulfoxide; EGF, epidermal growth factor; EtGly, ethylene glycol; GAM, goat anti-mouse; LR, local replicate; PBS, phosphate buffered saline; PEG 1000, polyethylene glycol 1000 Da; RAG, rabbit anti-goat; RFU, relative fluorescence unit; RR, random replicate, RS1, replicate slide 1; RS2, replicate slide 2, RS3, replicate slide 3; SM, slide model; SM1, SuperAldehyde 2; SM2, 2D-Aldehyde; SM3, SuperEpoxy 2; SM4, epoxy functionalized Slide E; SM5, nitrocellulose functionalized Protein Microarray; SNR, signal-to-noise ratio; SRR, structured random replicate; WSCV, wholeslide CV; WSM, whole-slide mean.
\end{abstract}


Table S1: List of names, catalogue number, and lot number for every protein and antibodies used in experiments.

\begin{tabular}{|c|c|c|}
\hline Antibody & Catalogue Number & Lot Number \\
\hline \multicolumn{3}{|c|}{ ThermoFisher Scientific } \\
\hline $\begin{array}{l}\text { Donkey anti-goat (DAG) IgG (H+L) } \\
\text { Cross-Adsorbed Secondary Antibody, } \\
\text { Alexa Fluor } 488 \text { (AF488) }\end{array}$ & A11055 & 1827671 \\
\hline $\begin{array}{l}\text { RAG IgG (H+L) Cross-Adsorbed } \\
\text { Secondary Antibody, AF488 }\end{array}$ & A11078 & 1757125 \\
\hline $\begin{array}{c}\text { Chicken anti-goat (CAG) IgG (H+L) } \\
\text { Cross-Adsorbed Secondary Antibody, } \\
\text { AF488 }\end{array}$ & A21467 & 1830314 \\
\hline $\begin{array}{c}\text { DAG IgG (H+L) Cross-Adsorbed } \\
\text { Secondary Antibody, Alexa Fluor } 647 \\
\text { (AF647) }\end{array}$ & A21447 & 1841382 \\
\hline $\begin{array}{l}\text { RAG IgG (H+L) Cross-Adsorbed } \\
\text { Secondary Antibody, AF647 }\end{array}$ & A21446 & 1848463 \\
\hline $\begin{array}{l}\text { CAG IgG (H+L) Cross-Adsorbed } \\
\text { Secondary Antibody, AF647 }\end{array}$ & A21469 & 1882197 \\
\hline $\begin{array}{c}\text { Goat anti-Mouse (GAM) IgG (H+L) Cross- } \\
\text { Adsorbed Secondary Antibody, Alexa } \\
\text { Fluor } 546 \text { (AF546) }\end{array}$ & A11003 & 1809360 \\
\hline $\begin{array}{l}\text { GAM IgG }(\mathrm{H}+\mathrm{L}) \text { Cross-Adsorbed } \\
\text { Secondary Antibody, AF647 }\end{array}$ & A21235 & 1868116 \\
\hline \multicolumn{3}{|c|}{ R\&D SYSTEMS } \\
\hline $\begin{array}{l}\text { Human/Primate EGF Antibody } \\
\text { Monoclonal Mouse IgG } 1\end{array}$ & MAB636-100 & AWQ1117121 \\
\hline Recombinant Human EGF & 236-EG-200 & HLM8217101 \\
\hline $\begin{array}{l}\text { Human/Primate Biotinylated Antibody } \\
\text { Antigen Affinity-purified Polyclonal Goat } \\
\text { IgG }\end{array}$ & BAF236 & ARA0615091 \\
\hline
\end{tabular}


Table S2: Hygroscopic additive content for the 28 buffers used for slide-buffer optimization, with 1,3-But, 1,3-butanediol; 2,3-But, 2,3-butanediol; betaine; DMSO, dimethyl sulfoxide; EtGly, ethylene glycol; PEG 1000, polyethylene glycol 1000 Da.

\begin{tabular}{|c|c|c|c|c|c|c|c|}
\hline & PEG 1000 & Glycerol & DMSO & EtGly & 1,3-But & 2,3-But & Betaine \\
\hline PEG 1000 & $\begin{array}{c}\text { B1 } \\
\text { PEG } 100030 \%\end{array}$ & & & & & & \\
\hline Glycerol & $\begin{array}{c}\text { B8 } \\
\text { PEG } 100015 \% \\
\text { Glycerol 15\% }\end{array}$ & $\begin{array}{c}\text { B2 } \\
\text { Glycerol 30\% }\end{array}$ & & & & & \\
\hline DMSO & $\begin{array}{c}\text { B9 } \\
\text { PEG } 100015 \% \\
\text { DMSO 15\% }\end{array}$ & $\begin{array}{c}\text { B14 } \\
\text { Glycerol 15\% } \\
\text { DMSO } 15 \%\end{array}$ & $\begin{array}{c}\text { B3 } \\
\text { DMSO 30\% }\end{array}$ & & & & \\
\hline EtGly & $\begin{array}{c}\text { B10 } \\
\text { PEG } 1000 \text { 15\% } \\
\text { EtGly } 15 \%\end{array}$ & $\begin{array}{c}\text { B15 } \\
\text { Glycerol 15\% } \\
\text { EtGly } 15 \%\end{array}$ & $\begin{array}{c}\text { B19 } \\
\text { DMSO 15\% } \\
\text { EtGly } 15 \%\end{array}$ & $\begin{array}{c}\text { B4 } \\
\text { EtGly } 30 \%\end{array}$ & & & \\
\hline 1,3-But & $\begin{array}{c}\text { B11 } \\
\text { PEG 1000 15\% } \\
\text { 1,3-But 15\% }\end{array}$ & $\begin{array}{c}\text { B16 } \\
\text { Glycerol 15\% } \\
\text { 1,3-But } 15 \%\end{array}$ & $\begin{array}{c}\text { B20 } \\
\text { DMSO 15\% } \\
\text { 1,3-But 15\% }\end{array}$ & $\begin{array}{c}\text { B23 } \\
\text { EtGly 15\% } \\
\text { 1,3-But 15\% }\end{array}$ & $\begin{array}{c}\text { B5 } \\
\text { 1,3-But } 30 \%\end{array}$ & & \\
\hline 2,3-But & $\begin{array}{c}\text { B12 } \\
\text { PEG } 1000 \text { 15\% } \\
\text { 2,3-But 15\% }\end{array}$ & $\begin{array}{c}\text { B17 } \\
\text { Glycerol 15\% } \\
\text { 2,3-But 15\% }\end{array}$ & $\begin{array}{c}\text { B21 } \\
\text { DMSO 15\% } \\
\text { 2,3-But 15\% }\end{array}$ & $\begin{array}{c}\text { B24 } \\
\text { EtGly 15\% } \\
\text { 2,3-But 15\% }\end{array}$ & $\begin{array}{c}\text { B26 } \\
\text { 1,3-But 15\% } \\
\text { 2,3-But 15\% }\end{array}$ & $\begin{array}{c}\text { B6 } \\
\text { 2,3-But } 30 \%\end{array}$ & \\
\hline Betaine & $\begin{array}{c}\text { B13 } \\
\text { PEG } 100015 \% \\
\text { Betaine } 1 \mathrm{M}\end{array}$ & $\begin{array}{c}\text { B18 } \\
\text { Glycerol 15\% } \\
\text { Betaine 1 M }\end{array}$ & $\begin{array}{c}\text { B22 } \\
\text { DMSO 15\% } \\
\text { Betaine 1 M }\end{array}$ & $\begin{array}{c}\text { B25 } \\
\text { EtGly 15\% } \\
\text { Betaine 1 M }\end{array}$ & $\begin{array}{c}\text { B27 } \\
\text { 1,3-But 15\% } \\
\text { Betaine 1 M }\end{array}$ & $\begin{array}{c}\text { B28 } \\
\text { 2,3-But 15\% } \\
\text { Betaine 1 M }\end{array}$ & $\begin{array}{c}\text { B7 } \\
\text { Betaine } 2 \mathrm{M}\end{array}$ \\
\hline
\end{tabular}


Table S3: Summary of all heatmaps generated. One heatmap was generated for every buffer-antibody combination. Hence, 9 heatmaps were produced per replicate slide, with 3 replicate slides (RS1-RS3) used for every SM. 5 SMs were used for the two experimental sets ( $c A b$ immobilization and analyte binding). This makes a total of $2 \times 5 \times 3 \times 9=270$ heatmaps generated with 54 heatmaps generated for every SM.

\begin{tabular}{|c|c|c|c|c|c|}
\hline Experiment Set & Slide Model & Replicate Slide & \multicolumn{3}{|c|}{ Buffer-Antibody Combination } \\
\hline \multirow{7}{*}{$\begin{array}{l}\text { Capture antibody } \\
\text { immobilization }\end{array}$} & \multirow{3}{*}{ SuperAldehyde 2 (SM1) } & \multirow[t]{2}{*}{ Replicate slide 1 (RS1) } & CV-RAG & SNR-RAG & PBS-RAG \\
\hline & & & $\mathrm{CV}-\mathrm{CAG}$ & SNR-CAG & PBS-CAG \\
\hline & & Replicate slide 2 (RS2) & \multicolumn{3}{|c|}{9 combinations per replicate } \\
\hline & 2D-Aldehyde (SM2) & RS1, RS2, RS3 & \multicolumn{3}{|c|}{9 combinations per replicate } \\
\hline & SuperEpoxy 2 (SM3) & $\mathrm{RS} 1, \mathrm{RS} 2, \mathrm{RS} 3$ & \multicolumn{3}{|c|}{9 combinations per replicate } \\
\hline & Slide E (SM4) & $\mathrm{RS} 1, \mathrm{RS} 2, \mathrm{RS} 3$ & \multicolumn{3}{|c|}{9 combinations per replicate } \\
\hline & Protein Microarray (SM5) & RS1, RS2, RS3 & \multicolumn{3}{|c|}{9 combinations per replicate } \\
\hline \multirow[t]{3}{*}{ Analyte binding } & SM3 & $\mathrm{RS} 1, \mathrm{RS} 2, \mathrm{RS} 3$ & \multicolumn{3}{|c|}{9 combinations per replicate } \\
\hline & SM4 & $\mathrm{RS} 1, \mathrm{RS} 2, \mathrm{RS} 3$ & \multicolumn{3}{|c|}{9 combinations per replicate } \\
\hline & SM5 & RS1, RS2, RS3 & \multicolumn{3}{|c|}{9 combinations per replicate } \\
\hline
\end{tabular}


Table S4: InnoScan 1100 AL emission filters specifications

\begin{tabular}{|c|c|c|}
\hline Excitation wavelength & Emission filter name & Wavelengths transmitted \\
\hline $635 \mathrm{~nm}$ & $677 / 45$ & $654.5-699.5 \mathrm{~nm}$ \\
\hline $532 \mathrm{~nm}$ & $579 / 34$ & $562-596 \mathrm{~nm}$ \\
\hline
\end{tabular}


Table S5: Summary of all CV of the analyte binding signal (spot value with and without background subtraction performed automatically by the ArrayPro software) and SNR averages (background subtracted) for the 6 SMs with 28 buffer combinations and PBS. The best performing buffers for CV (lowest CV and with a SNR that was at least 75\% of the mean SNR of all buffers for the given SM) and SNR (highest SNR and a CV lower than 10\%) are highlighted. The best performing buffers established in this work with respect to CV and SNR are colored green and orange, respectively. Note that, for SM3, buffers B3 were chosen in subsequent experiments since they gave good performance for CV and SNR simultaneously (Fig. S1).

\begin{tabular}{|c|c|c|c|c|c|c|c|c|c|c|c|c|c|c|c|}
\hline & \multicolumn{3}{|c|}{ Super Aldehyde 2 (SM1) } & \multicolumn{3}{|c|}{ 2D Aldehyde (SM2) } & \multicolumn{3}{|c|}{ Super Epox 2 (SM3) } & \multicolumn{3}{|c|}{ Slide E (SM4) } & \multicolumn{3}{|c|}{ Protein Microarray (SM5) } \\
\hline Buffer & $\begin{array}{c}\text { CV } \\
\text { (spot value } \\
\text { background } \\
\text { subtracted*) }\end{array}$ & $\begin{array}{c}\text { CV } \\
\text { (without } \\
\text { background } \\
\text { subtraction) }\end{array}$ & \begin{tabular}{|c|} 
SNR \\
(spot value \\
background \\
subtracted*) \\
\end{tabular} & $\begin{array}{c}\text { CV } \\
\text { (spot value } \\
\text { background } \\
\text { subtracted*) }\end{array}$ & $\begin{array}{c}\text { CV } \\
\text { (without } \\
\text { background } \\
\text { subtraction) } \\
\end{array}$ & \begin{tabular}{|c|} 
SNR \\
(spot value \\
background \\
subtracted*) \\
\end{tabular} & $\begin{array}{c}\text { CV } \\
\text { (spot value } \\
\text { background } \\
\text { subtracted*) }\end{array}$ & $\begin{array}{c}\text { CV } \\
\text { (without } \\
\text { background } \\
\text { subtraction) }\end{array}$ & $\begin{array}{c}\text { SNR } \\
\text { (spot value } \\
\text { background } \\
\text { subtracted*) } \\
\end{array}$ & \begin{tabular}{|c|} 
CV \\
$\begin{array}{c}\text { (spot value } \\
\text { background } \\
\text { subtracted }\end{array}$ \\
\end{tabular} & $\begin{array}{c}\text { CV } \\
\text { (without } \\
\text { background } \\
\text { subtraction) }\end{array}$ & $\begin{array}{c}\text { SNR } \\
\text { (spot value } \\
\text { background } \\
\text { subtracted*) }\end{array}$ & $\begin{array}{c}\text { CV } \\
\text { (spot value } \\
\text { background } \\
\text { subtracted*) }\end{array}$ & $\begin{array}{c}\text { CV } \\
\text { (without } \\
\text { background } \\
\text { subtraction) }\end{array}$ & $\begin{array}{c}\text { SNR } \\
\text { (spot value } \\
\text { background } \\
\text { subtracted*) }\end{array}$ \\
\hline 1 & $12.4 \%$ & \begin{tabular}{l|l}
$5.3 \%$ \\
\end{tabular} & 28 & $19.6 \%$ & $21.7 \%$ & 5 & $80.5 \%$ & 58.0\% & $\begin{array}{r}39 \\
\end{array}$ & $21.2 \%$ & $18.6 \%$ & \begin{tabular}{|l|}
107 \\
\end{tabular} & $12.8 \%$ & $10.7 \%$ & 42 \\
\hline 2 & $10.0 \%$ & $8.4 \%$ & 33 & $5.8 \%$ & $4.4 \%$ & 25 & $16.0 \%$ & $15.3 \%$ & 134 & $18.2 \%$ & $18.0 \%$ & 675 & $10.0 \%$ & $8.2 \%$ & 26 \\
\hline 3 & $10.9 \%$ & $10.7 \%$ & 156 & $13.4 \%$ & $10.4 \%$ & 27 & $7.3 \%$ & $7.2 \%$ & 1,308 & $11.5 \%$ & $11.5 \%$ & 457 & $8.6 \%$ & $7.9 \%$ & 51 \\
\hline 4 & $7.6 \%$ & $7.4 \%$ & 178 & $20.8 \%$ & $17.0 \%$ & 36 & $16.7 \%$ & $16.5 \%$ & 1,203 & $12.7 \%$ & $12.7 \%$ & 312 & $8.9 \%$ & $7.5 \%$ & 34 \\
\hline 5 & $9.4 \%$ & $9.2 \%$ & 108 & $17.4 \%$ & $15.8 \%$ & 19 & $10.2 \%$ & $10.1 \%$ & 325 & $77.5 \%$ & $74.0 \%$ & 45 & $10.3 \%$ & $8.7 \%$ & 27 \\
\hline 6 & $9.6 \%$ & $9.3 \%$ & 70 & $42.7 \%$ & $30.9 \%$ & 12 & $62.1 \%$ & $59.9 \%$ & 168 & $152.3 \%$ & $40.3 \%$ & 6 & $16.1 \%$ & $10.5 \%$ & 16 \\
\hline 7 & $8.2 \%$ & $6.9 \%$ & 43 & $8.8 \%$ & $6.3 \%$ & 29 & $13.2 \%$ & $12.8 \%$ & 105 & $7.9 \%$ & $7.8 \%$ & 327 & $17.4 \%$ & $10.9 \%$ & 14 \\
\hline 8 & $10.6 \%$ & $5.3 \%$ & 14 & $19.4 \%$ & $19.8 \%$ & 18 & $43.2 \%$ & $38.0 \%$ & 20 & $13.4 \%$ & $13.0 \%$ & 42 & $87.6 \%$ & $30.7 \%$ & 6 \\
\hline 9 & $7.2 \%$ & $6.9 \%$ & 49 & $14.3 \%$ & $13.5 \%$ & 5 & $74.4 \%$ & $64.5 \%$ & 47 & $23.0 \%$ & $21.5 \%$ & 102 & $13.7 \%$ & $12.7 \%$ & 90 \\
\hline 10 & $5.1 \%$ & $3.6 \%$ & 34 & $19.5 \%$ & $10.4 \%$ & 5 & $45.5 \%$ & $39.8 \%$ & 78 & $18.8 \%$ & $17.4 \%$ & 201 & $14.7 \%$ & $12.4 \%$ & 48 \\
\hline 11 & $10.1 \%$ & $4.9 \%$ & 15 & $13.5 \%$ & $13.6 \%$ & 5 & $41.9 \%$ & $35.2 \%$ & 38 & $22.2 \%$ & $20.8 \%$ & 181 & $13.6 \%$ & $11.9 \%$ & 58 \\
\hline 12 & $8.2 \%$ & $4.0 \%$ & 16 & $16.4 \%$ & $16.5 \%$ & 5 & $72.8 \%$ & $57.6 \%$ & 10 & $32.1 \%$ & $29.6 \%$ & 19 & $13.4 \%$ & $10.9 \%$ & 45 \\
\hline 13 & $12.2 \%$ & $11.7 \%$ & 179 & $6.3 \%$ & $5.9 \%$ & 24 & $12.4 \%$ & $11.9 \%$ & 166 & $8.8 \%$ & $8.7 \%$ & 65 & $11.6 \%$ & $10.3 \%$ & 62 \\
\hline 14 & $9.7 \%$ & $9.0 \%$ & 38 & $10.8 \%$ & $8.2 \%$ & 20 & $25.7 \%$ & $25.2 \%$ & 119 & $22.9 \%$ & $22.5 \%$ & 339 & $10.3 \%$ & $8.3 \%$ & 31 \\
\hline 15 & $12.3 \%$ & $10.4 \%$ & 26 & $10.1 \%$ & $7.6 \%$ & 21 & $29.7 \%$ & $28.9 \%$ & 143 & $18.3 \%$ & $18.1 \%$ & 811 & $14.5 \%$ & $9.8 \%$ & 19 \\
\hline 16 & $9.6 \%$ & $7.5 \%$ & 24 & $14.5 \%$ & $12.6 \%$ & 18 & $52.8 \%$ & $50.5 \%$ & 125 & $38.9 \%$ & $37.9 \%$ & 367 & $12.5 \%$ & $10.3 \%$ & 33 \\
\hline 17 & $15.3 \%$ & $8.6 \%$ & 14 & $15.9 \%$ & $12.9 \%$ & 19 & $67.9 \%$ & $64.5 \%$ & 77 & $29.8 \%$ & $29.6 \%$ & 24 & $11.9 \%$ & $9.9 \%$ & 33 \\
\hline 18 & $13.6 \%$ & $10.7 \%$ & 22 & $7.9 \%$ & $5.7 \%$ & 30 & $41.0 \%$ & $39.5 \%$ & 93 & $13.9 \%$ & $13.9 \%$ & 109 & $12.2 \%$ & $8.1 \%$ & 13 \\
\hline 19 & $10.5 \%$ & $10.3 \%$ & 194 & $27.5 \%$ & $22.0 \%$ & 30 & $14.8 \%$ & $14.7 \%$ & 400 & $14.2 \%$ & $14.1 \%$ & 1,294 & $10.0 \%$ & $8.9 \%$ & 56 \\
\hline 20 & $8.7 \%$ & $8.5 \%$ & 185 & $12.1 \%$ & $8.8 \%$ & 20 & $7.5 \%$ & $7.4 \%$ & 1,047 & $17.3 \%$ & $17.2 \%$ & 2,266 & $9.9 \%$ & $8.7 \%$ & 56 \\
\hline 21 & $7.7 \%$ & $7.4 \%$ & 111 & $13.3 \%$ & $9.4 \%$ & 17 & $7.8 \%$ & $7.7 \%$ & 1,533 & $9.8 \%$ & $9.7 \%$ & 667 & $8.6 \%$ & $7.8 \%$ & 50 \\
\hline 22 & $6.0 \%$ & $5.6 \%$ & 78 & $9.4 \%$ & $6.5 \%$ & 27 & $10.8 \%$ & $10.7 \%$ & 261 & $7.3 \%$ & $7.3 \%$ & 874 & $11.0 \%$ & $8.8 \%$ & 23 \\
\hline 23 & $7.1 \%$ & $6.7 \%$ & 97 & $14.4 \%$ & $12.9 \%$ & 13 & $8.0 \%$ & $7.9 \%$ & 432 & $17.8 \%$ & $17.3 \%$ & 798 & $7.7 \%$ & $6.2 \%$ & 33 \\
\hline 24 & $8.5 \%$ & $8.1 \%$ & 122 & $12.2 \%$ & $11.6 \%$ & 26 & $15.7 \%$ & $15.4 \%$ & 466 & $17.3 \%$ & $17.0 \%$ & 878 & $6.8 \%$ & $6.1 \%$ & 39 \\
\hline 25 & $6.9 \%$ & $6.3 \%$ & 73 & $8.3 \%$ & $5.1 \%$ & 28 & $7.1 \%$ & $6.9 \%$ & 322 & $9.7 \%$ & $9.6 \%$ & 1,122 & $10.2 \%$ & $8.2 \%$ & 23 \\
\hline 26 & $8.1 \%$ & $7.6 \%$ & 80 & $15.9 \%$ & $11.7 \%$ & 15 & $9.6 \%$ & $9.5 \%$ & 292 & $62.7 \%$ & $60.2 \%$ & 80 & $9.6 \%$ & $7.5 \%$ & 25 \\
\hline 27 & $7.2 \%$ & $6.0 \%$ & 48 & $8.7 \%$ & $5.9 \%$ & 30 & $5.5 \%$ & $5.2 \%$ & 142 & $12.8 \%$ & $12.6 \%$ & 1,313 & $14.0 \%$ & $9.1 \%$ & 15 \\
\hline 28 & $7.9 \%$ & $7.1 \%$ & 58 & $6.9 \%$ & $4.4 \%$ & 29 & $12.8 \%$ & $12.5 \%$ & 120 & $12.3 \%$ & $12.1 \%$ & 1,287 & $9.9 \%$ & $7.8 \%$ & 19 \\
\hline PBS & $13.2 \%$ & $12.9 \%$ & 193 & $11.5 \%$ & $10.0 \%$ & 18 & $7.5 \%$ & $7.5 \%$ & 1,104 & $8.1 \%$ & $8.0 \%$ & 1,073 & $7.6 \%$ & $6.7 \%$ & 43 \\
\hline
\end{tabular}

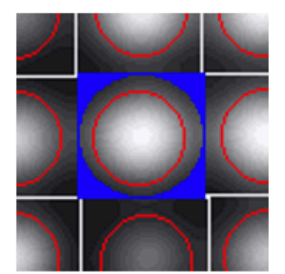




\begin{tabular}{|c|c|c|c|c|c|c|c|c|c|c|c|c|c|}
\hline & \multirow[b]{3}{*}{ BUFFER } & \multicolumn{6}{|c|}{ SLIDE-BUFFER CV VALUES } & \multicolumn{6}{|c|}{ SLIDE-BUFFER SNR VALUES } \\
\hline & & \multicolumn{2}{|c|}{ ALDEHYDE } & \multicolumn{2}{|c|}{ EPOXY } & \multicolumn{2}{|c|}{ NITROCELLULOSE } & \multicolumn{2}{|c|}{ ALDEHYDE } & \multicolumn{2}{|c|}{ EPOXY } & \multicolumn{2}{|c|}{ NITROCELLULOSE } \\
\hline & & $\begin{array}{c}\text { Super } \\
\text { Aldehyde } \\
2\end{array}$ & $\begin{array}{c}\text { 2D } \\
\text { Aldehyde }\end{array}$ & $\begin{array}{c}\text { Super } \\
\text { Epoxy } 2\end{array}$ & Slide E & $\begin{array}{c}\text { Protein } \\
\text { Micro- } \\
\text { array }\end{array}$ & $\begin{array}{l}\text { Super } \\
\text { Nitro }\end{array}$ & $\begin{array}{c}\text { Super } \\
\text { Aldehyde } \\
2\end{array}$ & $\begin{array}{c}\text { 2D } \\
\text { Aldehyde }\end{array}$ & $\begin{array}{c}\text { Super } \\
\text { Epoxy } 2\end{array}$ & Slide E & $\begin{array}{l}\text { Protein } \\
\text { Micro- } \\
\text { array }\end{array}$ & $\begin{array}{l}\text { Super } \\
\text { Nitro }\end{array}$ \\
\hline 1 & $30 \%$ PEG 1000 & 10.3 & 21.7 & 58.0 & 18.6 & 10.7 & 7.7 & 28 & 5 & 39 & 107 & 42 & 44 \\
\hline 2 & $30 \%$ Glycerol & 8.4 & 4.4 & 15.3 & 18.0 & 8.2 & 11.3 & 33 & 25 & 134 & 675 & 26 & 32 \\
\hline 3 & $30 \%$ DMSO & 10.7 & 10.4 & 7.2 & 11.5 & 7.9 & 6.3 & 156 & 27 & 1,308 & 457 & 51 & 36 \\
\hline 4 & $30 \%$ Ethylene Glycol & 7.4 & 17.0 & 16.5 & 12.7 & 7.5 & 6.9 & 178 & 36 & 1,203 & 312 & 34 & 30 \\
\hline 5 & $30 \%$ 1,3-butanediol & 9.2 & 15.8 & 10.1 & 74.0 & 8.7 & 7.6 & 108 & 19 & 325 & 45 & 27 & 31 \\
\hline 6 & $30 \%$ 2,3-butanediol & 9.3 & 30.9 & 59.9 & 40.3 & 10.5 & 6.7 & 70 & 12 & 168 & 6 & 16 & 27 \\
\hline 7 & 2 M Betaine & 6.9 & 6.3 & 12.8 & 7.8 & 10.9 & 12.3 & 43 & 29 & 105 & 327 & 14 & 48 \\
\hline 8 & $15 \%$ PEG $1000,15 \%$ Glycerol & 5.3 & 19.8 & 38.0 & 13.0 & 30.7 & 6.1 & 14 & 18 & 20 & 42 & 6 & 16 \\
\hline 9 & $15 \%$ PEG 1000, 15\% DMSO & 6.9 & 13.5 & 64.5 & 21.5 & 12.7 & 5.4 & 49 & 5 & 47 & 102 & 90 & 19 \\
\hline 10 & 15\% PEG 1000, 15\% EtGly & 3.6 & 10.4 & 39.8 & 17.4 & 12.4 & 5.8 & 34 & 5 & 78 & 201 & 48 & 27 \\
\hline 11 & 15\% PEG 1000, 15\% 1,3 But. & 4.9 & 13.6 & 35.2 & 20.8 & 11.9 & 6.4 & 15 & 5 & 38 & 181 & 58 & 26 \\
\hline 12 & $15 \%$ PEG $1000,15 \% 2,3$ But. & 4.0 & 16.5 & 57.6 & 29.6 & 10.9 & 6.8 & 16 & 5 & 10 & 19 & 45 & 26 \\
\hline 13 & 15\% PEG 1000, 1 M Betaine & 11.7 & 5.9 & 11.9 & 8.7 & 10.3 & 5.8 & 179 & 24 & 166 & 65 & 62 & 50 \\
\hline 14 & $15 \%$ Glycerol, $15 \%$ DMSO & 9.0 & 8.2 & 25.2 & 22.5 & 8.3 & 5.8 & 38 & 20 & 119 & 339 & 31 & 30 \\
\hline 15 & $15 \%$ Glycerol, $15 \%$ EtGly & 10.4 & 7.6 & 28.9 & 18.1 & 9.8 & 7.3 & 26 & 21 & 143 & 811 & 19 & 25 \\
\hline 16 & $15 \%$ Glycerol, 15\% 1,3 But. & 7.5 & 12.6 & 50.5 & 37.9 & 10.3 & 6.3 & 24 & 18 & 125 & 367 & 33 & 30 \\
\hline 17 & $15 \%$ Glycerol, 15\% 2,3 But & 8.6 & 12.9 & 64.5 & 29.6 & 9.9 & 6.5 & 14 & 19 & 77 & 24 & 33 & 25 \\
\hline 18 & 15\% Glycerol, 1 M Betaine & 10.7 & 5.7 & 39.5 & 13.9 & 8.1 & 12.7 & 22 & 30 & 93 & 109 & 13 & 35 \\
\hline 19 & 15\% DMSO, 15\% EtGly & 10.3 & 22.0 & 14.7 & 14.1 & 8.9 & 6.3 & 194 & 30 & 400 & 1,294 & 56 & 25 \\
\hline 20 & 15\% DMSO, 15\% 1,3 But. & 8.5 & 8.8 & 7.4 & 17.2 & 8.7 & 4.4 & 185 & 20 & 1,047 & 2,266 & 56 & 25 \\
\hline 21 & 15\% DMSO, 15\% 2,3 But. & 7.4 & 9.4 & 7.7 & 9.7 & 7.8 & 4.0 & 111 & 17 & 1,533 & 667 & 50 & 26 \\
\hline 22 & 15\% DMSO, 1 M Betaine & 5.6 & 6.5 & 10.7 & 7.3 & 8.8 & 7.2 & 78 & 27 & 261 & 874 & 23 & 35 \\
\hline 23 & $15 \%$ EtGly, $15 \% 1,3$ But. & 6.7 & 12.9 & 7.9 & 17.3 & 6.2 & 6.9 & 97 & 13 & 432 & 798 & 33 & 21 \\
\hline 24 & $15 \%$ EtGly, 15\% 2,3 But. & 8.1 & 11.6 & 15.4 & 17.0 & 6.1 & 5.0 & 122 & 26 & 466 & 878 & 39 & 25 \\
\hline 25 & 15\% EtGly, 1 M Betaine & 6.3 & 5.1 & 6.9 & 9.6 & 8.2 & 9.4 & 73 & 28 & 322 & 1,122 & 23 & 38 \\
\hline 26 & $15 \%$ 1,3 But., 15\% 2,3 But. & 7.6 & 11.7 & 9.5 & 60.2 & 7.5 & 6.6 & 80 & 15 & 292 & 80 & 25 & 25 \\
\hline 27 & 15\% 1,3 But., 1 M Betaine & 6.0 & 5.9 & 5.2 & 12.6 & 9.1 & 7.3 & 48 & 30 & 142 & 1,313 & 15 & 31 \\
\hline 28 & 15\% 2,3 But., $1 \mathrm{M}$ Betaine & 7.1 & 4.4 & 12.5 & 12.1 & 7.8 & 7.3 & 58 & 29 & 120 & 1,287 & 19 & 36 \\
\hline 29 & PBS & 12.9 & 10.0 & 7.5 & 8.0 & 6.7 & 10.2 & 193 & 18 & 1,104 & 1,073 & 43 & 43 \\
\hline
\end{tabular}

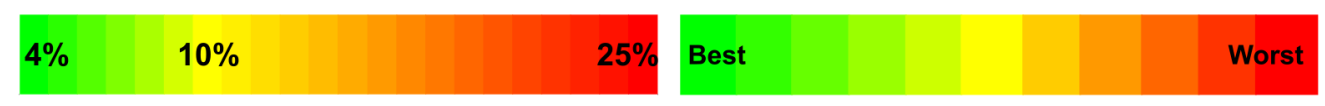

\begin{tabular}{|c|c|c|c|c|c|c|}
\hline \multirow[b]{2}{*}{ B } & \multicolumn{3}{|c|}{ TOP CV BUFFERS } & \multicolumn{3}{|c|}{ TOP SNR BUFFERS } \\
\hline & $\begin{array}{c}\text { Buffer } \\
\#\end{array}$ & CV & SNR & $\begin{array}{c}\text { Buffer } \\
\#\end{array}$ & CV & SNR \\
\hline \multirow{3}{*}{$\begin{array}{c}\text { Super } \\
\text { Aldehyde } 2\end{array}$} & 22 & $5.6 \%$ & 78 & 20 & $8.5 \%$ & 185 \\
\hline & 25 & $6.3 \%$ & 73 & 4 & $7.4 \%$ & 178 \\
\hline & 23 & $6.7 \%$ & 97 & 24 & $8.1 \%$ & 122 \\
\hline \multirow{3}{*}{$\begin{array}{l}\text { PolyAn 2D } \\
\text { Aldehyde }\end{array}$} & 28 & $4.4 \%$ & 29 & 18 & $5.7 \%$ & 30 \\
\hline & 2 & $4.4 \%$ & 25 & 27 & $5.9 \%$ & 30 \\
\hline & 25 & $5.1 \%$ & 28 & 28 & $4.4 \%$ & 29 \\
\hline \multirow{3}{*}{$\begin{array}{c}\text { Super Epoxy } \\
2\end{array}$} & 25 & $6.9 \%$ & 322 & 21 & $7.7 \%$ & 1'533 \\
\hline & 3 & $7.2 \%$ & $1^{\prime} 308$ & 3 & $7.2 \%$ & 1'308 \\
\hline & 20 & $7.4 \%$ & ו'047 & PBS & $7.5 \%$ & ا'104 r r r r \\
\hline \multirow{3}{*}{$\begin{array}{l}\text { Nexterion } \\
\text { Slide E }\end{array}$} & 22 & $7.3 \%$ & 874 & 25 & $9.6 \%$ & ا'122 \\
\hline & PBS & $8.0 \%$ & 1'073 & PBS & $8.0 \%$ & ו'073 \\
\hline & 25 & $9.6 \%$ & 1'122 & 22 & $7.3 \%$ & 874 \\
\hline \multirow{3}{*}{$\begin{array}{c}\text { Intuitive } \\
\text { Bioscience }\end{array}$} & 24 & $6.1 \%$ & 39 & 20 & $8.7 \%$ & 56 \\
\hline & 23 & $6.2 \%$ & 33 & 19 & $8.9 \%$ & 56 \\
\hline & PBS & $6.7 \%$ & 43 & 3 & $7.9 \%$ & 51 \\
\hline \multirow{3}{*}{ Super Nitro } & 21 & $4.0 \%$ & 26 & 13 & $5.8 \%$ & 50 \\
\hline & 20 & $4.4 \%$ & 25 & 1 & $7.7 \%$ & 44 \\
\hline & 24 & $5.0 \%$ & 25 & 25 & $9.4 \%$ & 38 \\
\hline
\end{tabular}

Figure S1. A. Summary of all CV and SNR averages for the 6 SMs with 28 buffer combinations and PBS. Color map is applied to all buffers for CV values whereas every buffer has its own colour map for SNR. The choice of buffer and additives has a large effect on CV and SNR and is highly dependent on each slide model. SuperNitro slides from Arrayit were tested in this experiment but left out for further testing because the autofocus of our scanner did not focus on the top surface of the nitrocellulose layer with the spots. B. Summary table of the best performing buffers for CV (lowest CV and with a SNR that was at least 75\% of the mean SNR of all buffers for the given SM) and SNR (highest SNR and a CV lower than 10\%). Color map is from best (green) to red (worst). 


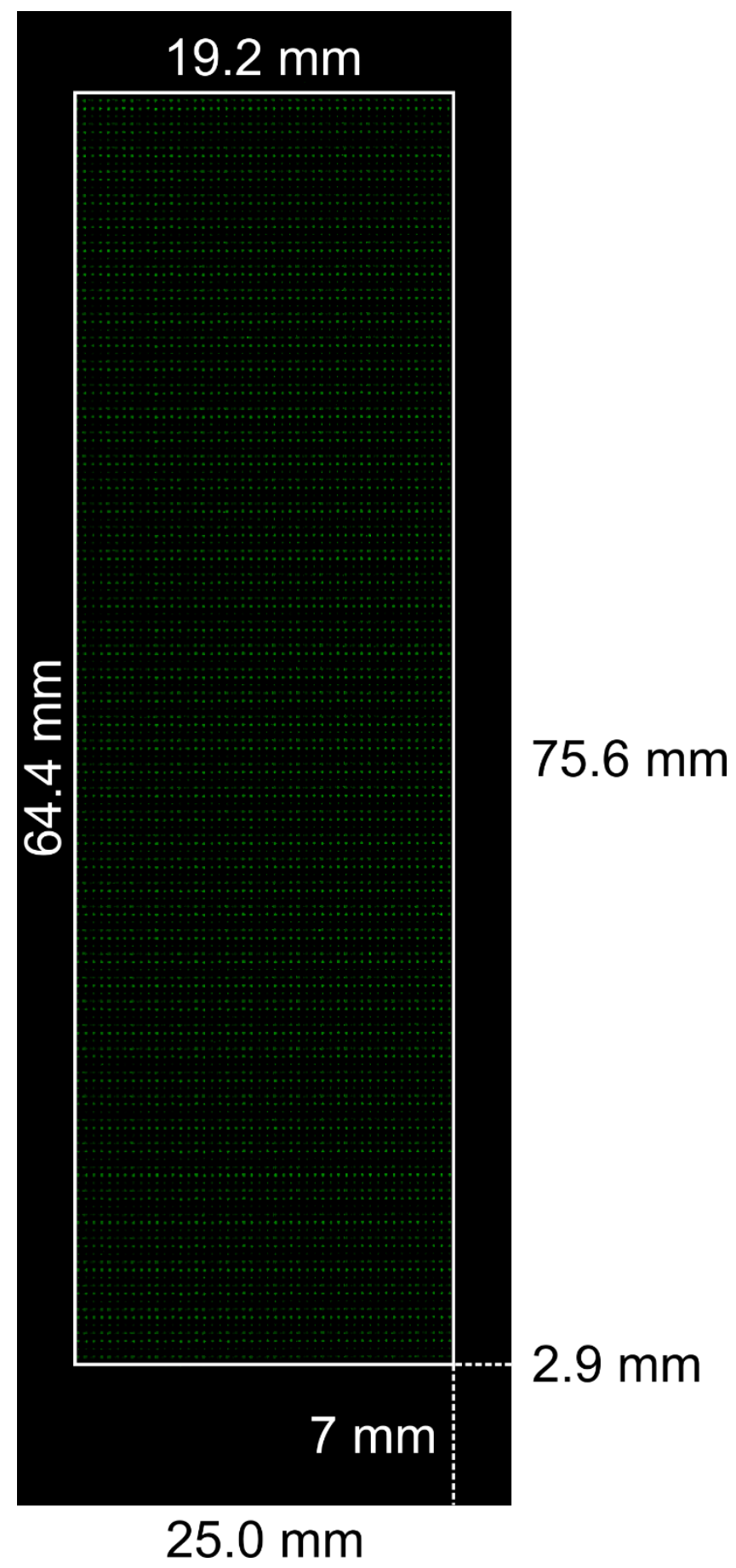

Figure S2. Raw image of the analyte binding 2D-Aldehyde (SM2)-RS2 overlapping arrays and schematic of slide and array dimensions. The left and right edges are identical, while the bottom edge is $7 \mathrm{~mm}$ and the top edge is approximately $4.2 \mathrm{~mm}$ (depending on slide size). 

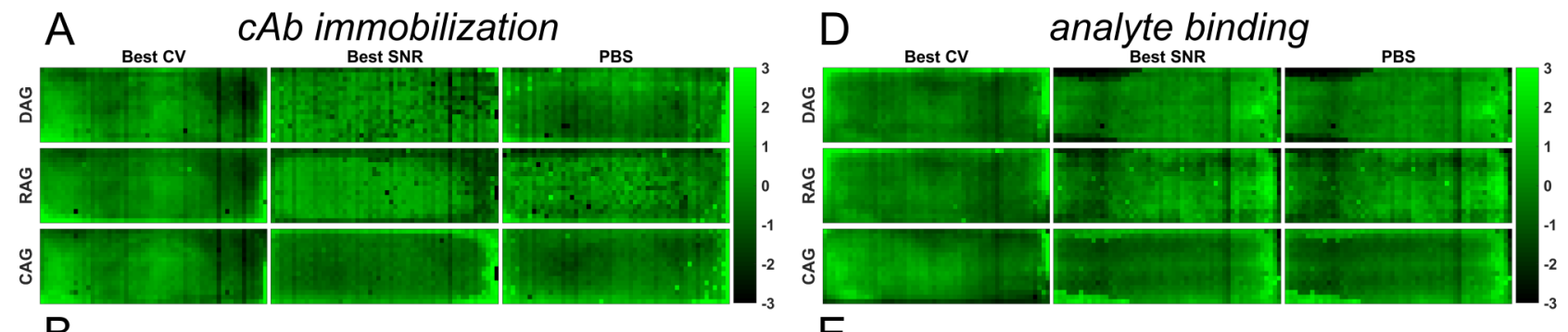
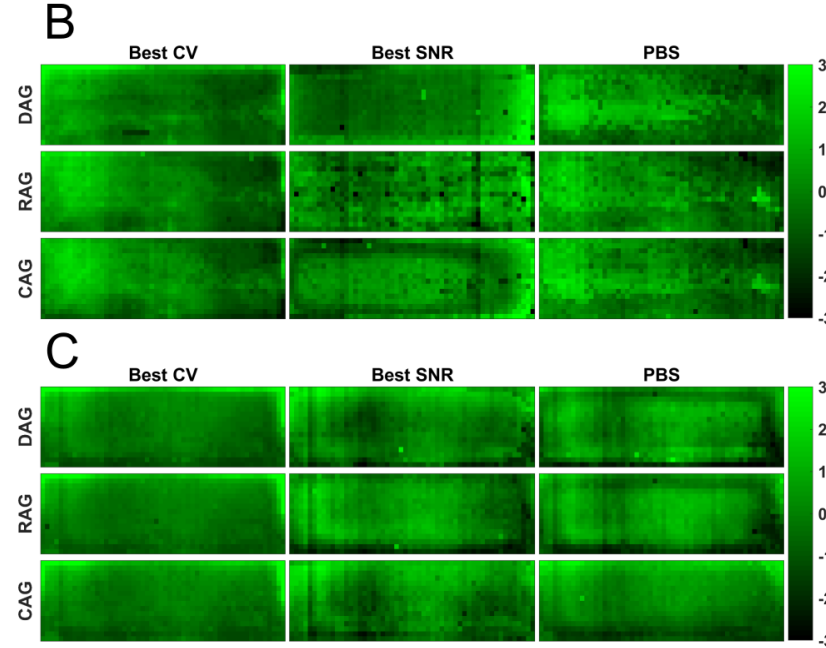

G

cAb immobilization

\begin{tabular}{ll|c|c|c|} 
& & \multicolumn{1}{c}{ Best CV } & \multicolumn{1}{c}{ Best SNR } & \multicolumn{1}{c}{ PBS } \\
\cline { 3 - 5 } & DAG & $12.8 \%$ & $8.2 \%$ & $6.5 \%$ \\
\cline { 3 - 5 } RS1 & RAG & $17.0 \%$ & $13.2 \%$ & $9.8 \%$ \\
\cline { 3 - 5 } & CAG & $14.3 \%$ & $15.6 \%$ & $11.2 \%$ \\
\cline { 3 - 5 } & & &
\end{tabular}

RS2

DAG

$-$

CAG

\begin{tabular}{|l|l|l|}
\hline $33.2 \%$ & $16.9 \%$ & $27.4 \%$ \\
\hline $29.4 \%$ & $14.8 \%$ & $13.3 \%$ \\
\hline $26.4 \%$ & $17.6 \%$ & $17.3 \%$ \\
\hline
\end{tabular}

DAG

RS3

\section{$E$}

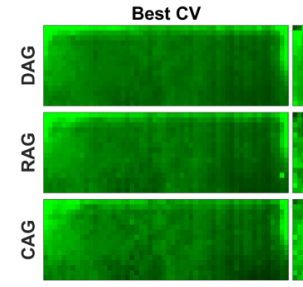

Best SNR

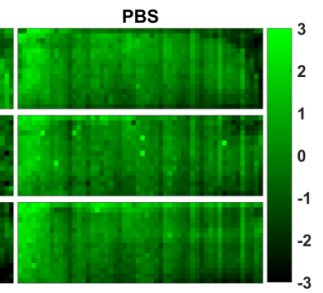

$\mathrm{F}$
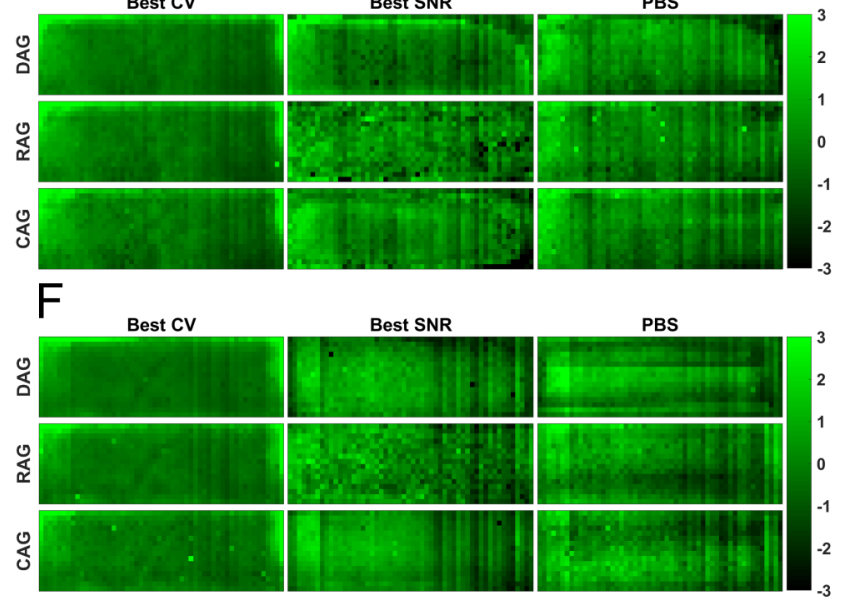

analyte binding

\begin{tabular}{|c|c|c|}
\hline Best CV & \multicolumn{1}{c}{ Best SNR } & \multicolumn{1}{c}{ PBS } \\
\hline $20.8 \%$ & $20.7 \%$ & $20.7 \%$ \\
\hline $20.2 \%$ & $15.8 \%$ & $15.8 \%$ \\
\hline $22.9 \%$ & $23.3 \%$ & $23.3 \%$ \\
\hline
\end{tabular}

\begin{tabular}{|c|c|c|}
\hline $45.7 \%$ & $16.1 \%$ & $16.7 \%$ \\
\hline $39.3 \%$ & $11.4 \%$ & $13.9 \%$ \\
\hline $35.8 \%$ & $12.8 \%$ & $13.9 \%$ \\
\hline $46.3 \%$ & $17.6 \%$ & $28.6 \%$ \\
\hline $37.0 \%$ & $9.6 \%$ & $20.4 \%$ \\
\hline $44.4 \%$ & $16.0 \%$ & $16.2 \%$ \\
\hline
\end{tabular}

$\begin{array}{llllllllllllllllllllll}4 \% & 5 \% & 6 \% & 7 \% & 8 \% & 9 \% & 10 \% & 11 \% & 12 \% & 13 \% & 14 \% & 15 \% & 16 \% & 17 \% & 18 \% & 19 \% & 20 \% & 21 \% & 22 \% & 23 \% & 24 \% & 25 \%\end{array}$

Figure S3: Normalized, contrast enhanced fluorescent heatmaps in the 677-emission channel for the SuperAldehyde 2 (SM1) slides revealing spatial variation and bias. Each panel demonstrates the nine heat maps for a single replicate slide. Each pixel represents the normalized fluorescence signal of a single spot after signal analysis and the color bar is centered on the whole slide mean (WSM) (0) and extends to \pm 3 standard deviation. Based on results in analyte binding, the best CV buffer is B22 and the best SNR buffer is B20 (see Fig. 1C). A-C. Heatmaps for the three replicate slides of capture antibody immobilization experiment. D-F. Heatmaps for the three replicate slides of the analyte binding antibody experiment. Different slides were used for capture antibody immobilization and analyte binding experiments. G. WSCV values (no background subtraction) for every individual heatmap. 

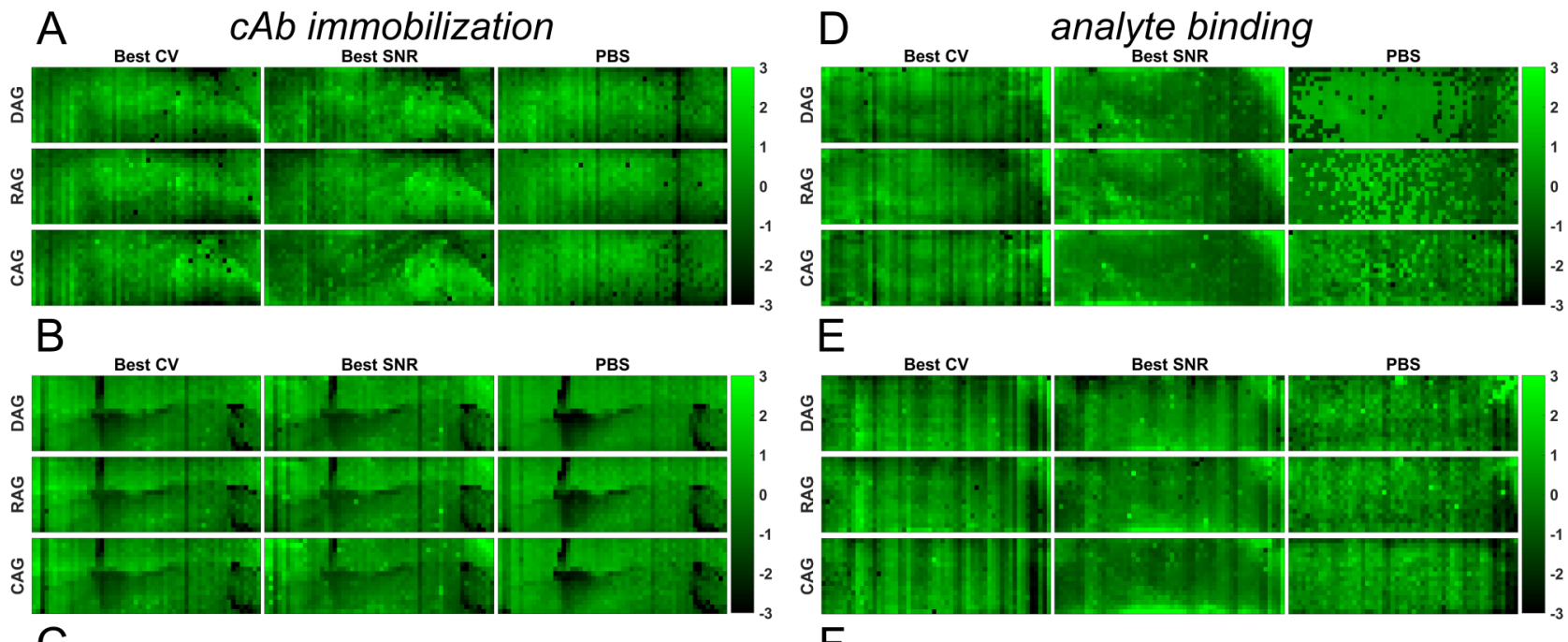

\section{E}
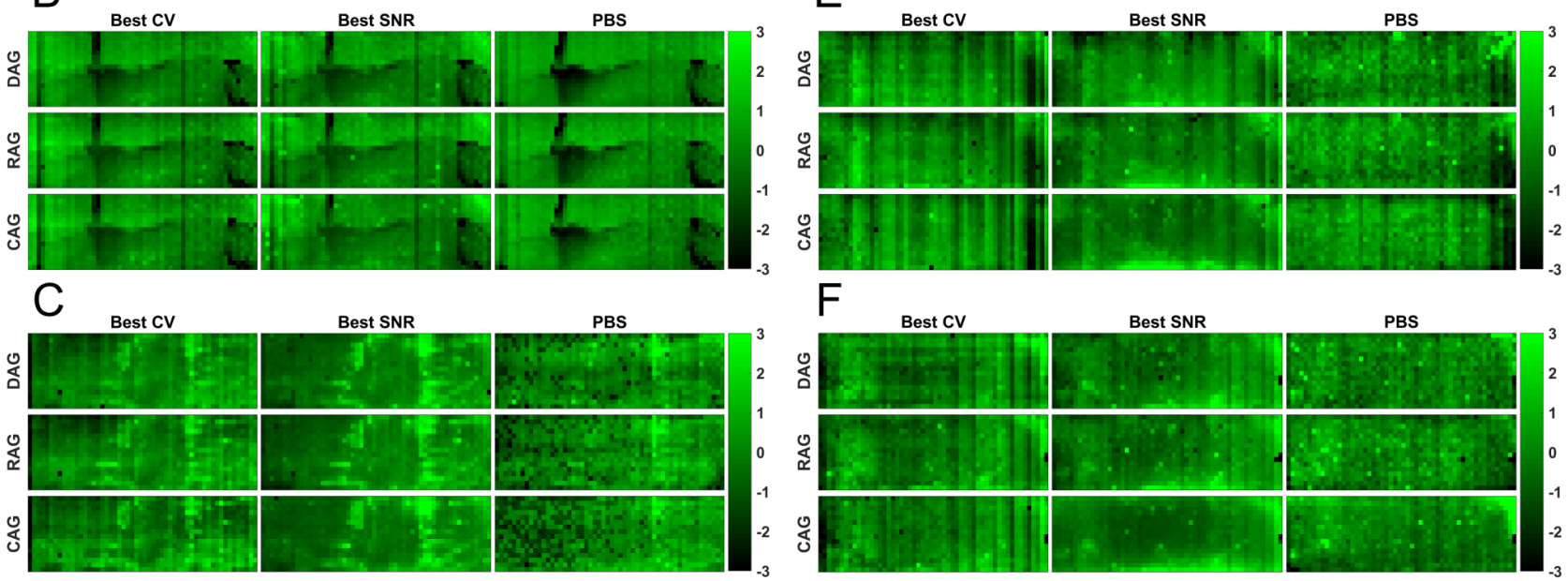

\begin{tabular}{|c|c|c|c|c|c|c|c|}
\hline \multicolumn{2}{|c|}{$G$} & \multicolumn{3}{|c|}{$c A b$ immobilization } & \multicolumn{3}{|c|}{ analyte binding } \\
\hline \multirow{4}{*}{ RS1 } & \multirow{4}{*}{$\begin{array}{l}\text { DAG } \\
\text { RAG } \\
\text { CAG }\end{array}$} & Best CV & Best SNR & PBS & Best CV & Best SNR & PBS \\
\hline & & $4.8 \%$ & $5.8 \%$ & $5.1 \%$ & $4.9 \%$ & $10.7 \%$ & $26.8 \%$ \\
\hline & & $4.6 \%$ & $6.5 \%$ & $6.3 \%$ & $6.4 \%$ & $9.5 \%$ & $20.0 \%$ \\
\hline & & $3.7 \%$ & $9.8 \%$ & $6.1 \%$ & $3.2 \%$ & $16.2 \%$ & $7.8 \%$ \\
\hline \multirow{3}{*}{ RS2 } & \multirow{3}{*}{$\begin{array}{l}\text { DAG } \\
\text { RAG } \\
\text { CAG }\end{array}$} & $10.1 \%$ & $14.0 \%$ & $12.0 \%$ & $8.0 \%$ & $9.9 \%$ & $11.4 \%$ \\
\hline & & $8.8 \%$ & $11.6 \%$ & $9.6 \%$ & $9.1 \%$ & $14.5 \%$ & $11.6 \%$ \\
\hline & & $7.8 \%$ & $14.1 \%$ & $10.9 \%$ & $5.5 \%$ & $17.1 \%$ & $10.4 \%$ \\
\hline \multirow{3}{*}{ RS3 } & DAG & $6.7 \%$ & $14.0 \%$ & $5.6 \%$ & $6.3 \%$ & $10.1 \%$ & $10.7 \%$ \\
\hline & RAG & $6.0 \%$ & $13.8 \%$ & $6.5 \%$ & $7.5 \%$ & $13.2 \%$ & $10.8 \%$ \\
\hline & CAG & $4.5 \%$ & $16.8 \%$ & $10.3 \%$ & $5.2 \%$ & $23.4 \%$ & $11.0 \%$ \\
\hline
\end{tabular}

\begin{tabular}{lllllllllllllllllllllll}
$4 \%$ & $5 \%$ & $6 \%$ & $7 \%$ & $8 \%$ & $9 \%$ & $10 \%$ & $11 \%$ & $12 \%$ & $13 \%$ & $14 \%$ & $15 \%$ & $16 \%$ & $17 \%$ & $18 \%$ & $19 \%$ & $20 \%$ & $21 \%$ & $22 \%$ & $23 \%$ & $24 \%$ & $25 \%$ \\
\hline
\end{tabular}

Figure S4: Normalized, contrast enhanced fluorescent heatmaps in the 677-emission channel for the 2D-Aldehyde (SM2) slides revealing spatial variation and bias. Each panel demonstrates the nine heat maps for a single replicate slide. Each pixel represents the normalized fluorescence signal of a single spot after signal analysis and the color bar is centered on the whole slide mean (WSM) (0) and extends to \pm 3 standard deviation. Based on results in analyte binding, the best CV buffer is B28 and the best SNR buffer is B18 (see Fig. 1C). A-C. Heatmaps for the three replicate slides of capture antibody immobilization experiment. D-F. Heatmaps for the three replicate slides of the analyte binding antibody experiment. Different slides were used for capture antibody immobilization and analyte binding experiments. G. WSCV values (no background subtraction) for every individual heatmap. 

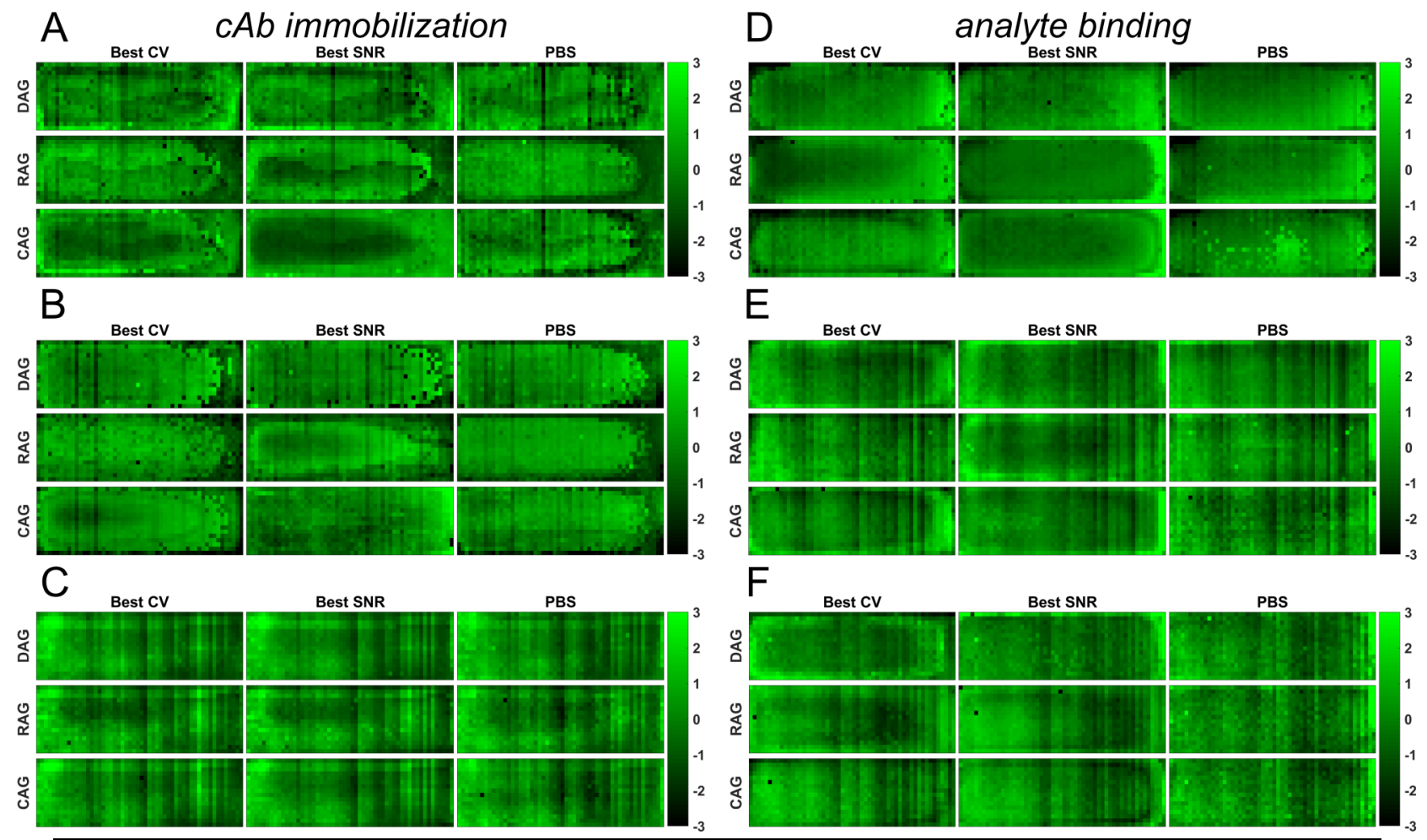

\begin{tabular}{|c|c|c|c|c|c|c|c|}
\hline \multicolumn{2}{|c|}{$G$} & \multicolumn{3}{|c|}{ cAb immobilization } & \multicolumn{3}{|c|}{ analyte binding } \\
\hline \multirow{4}{*}{ RS1 } & \multirow{4}{*}{$\begin{array}{l}\text { DAG } \\
\text { RAG } \\
\text { CAG }\end{array}$} & Best CV & Best SNR & PBS & Best CV & Best SNR & PBS \\
\hline & & $6.2 \%$ & $7.0 \%$ & $5.6 \%$ & $15.6 \%$ & $13.8 \%$ & $16.5 \%$ \\
\hline & & $15.0 \%$ & $12.7 \%$ & $15.2 \%$ & $23.2 \%$ & $30.9 \%$ & $17.1 \%$ \\
\hline & & $9.8 \%$ & $18.4 \%$ & $5.8 \%$ & $11.4 \%$ & $30.9 \%$ & $12.4 \%$ \\
\hline \multirow{3}{*}{ RS2 } & \multirow{3}{*}{$\begin{array}{l}\text { DAG } \\
\text { RAG } \\
\text { CAG }\end{array}$} & $7.6 \%$ & $6.0 \%$ & $8.1 \%$ & $17.0 \%$ & $17.6 \%$ & $14.9 \%$ \\
\hline & & $16.1 \%$ & $12.3 \%$ & $17.8 \%$ & $13.0 \%$ & $13.1 \%$ & $13.3 \%$ \\
\hline & & $10.5 \%$ & $13.4 \%$ & $9.8 \%$ & $12.7 \%$ & $16.5 \%$ & $13.0 \%$ \\
\hline \multirow{3}{*}{ RS3 } & \multirow{3}{*}{$\begin{array}{l}\text { DAG } \\
\text { RAG } \\
\text { CAG }\end{array}$} & $13.5 \%$ & $13.8 \%$ & $10.7 \%$ & $30.0 \%$ & $23.7 \%$ & $18.8 \%$ \\
\hline & & $15.0 \%$ & $15.4 \%$ & $11.2 \%$ & $23.0 \%$ & $21.1 \%$ & $17.7 \%$ \\
\hline & & $11.9 \%$ & $12.5 \%$ & $10.5 \%$ & $16.2 \%$ & $19.6 \%$ & $18.0 \%$ \\
\hline
\end{tabular}

\begin{tabular}{llllllllllllllllllllllll}
$4 \%$ & $5 \%$ & $6 \%$ & $7 \%$ & $8 \%$ & $9 \%$ & $10 \%$ & $11 \%$ & $12 \%$ & $13 \%$ & $14 \%$ & $15 \%$ & $16 \%$ & $17 \%$ & $18 \%$ & $19 \%$ & $20 \%$ & $21 \%$ & $22 \%$ & $23 \%$ & $24 \%$ & $25 \%$ \\
\hline
\end{tabular}

Figure S5: Normalized, contrast enhanced fluorescent heatmaps in the 677-emission channel for the SuperEpoxy 2 (SM3) slides revealing spatial variation and bias. Each panel demonstrates the nine heat maps for a single replicate slide. Each pixel represents the normalized fluorescence signal of a single spot after signal analysis and the color bar is centered on the whole slide mean (WSM) (0) and extends to \pm 3 standard deviation. Based on results in analyte binding, the best CV buffer is B3 and the best SNR buffer is B20 (see Fig. 1C). A-C. Heatmaps for the three replicate slides of capture antibody immobilization experiment. D-F. Heatmaps for the three replicate slides of the analyte binding antibody experiment. Different slides were used for capture antibody immobilization and analyte binding experiments. G. CV values (no background subtraction) for every individual heatmap. 

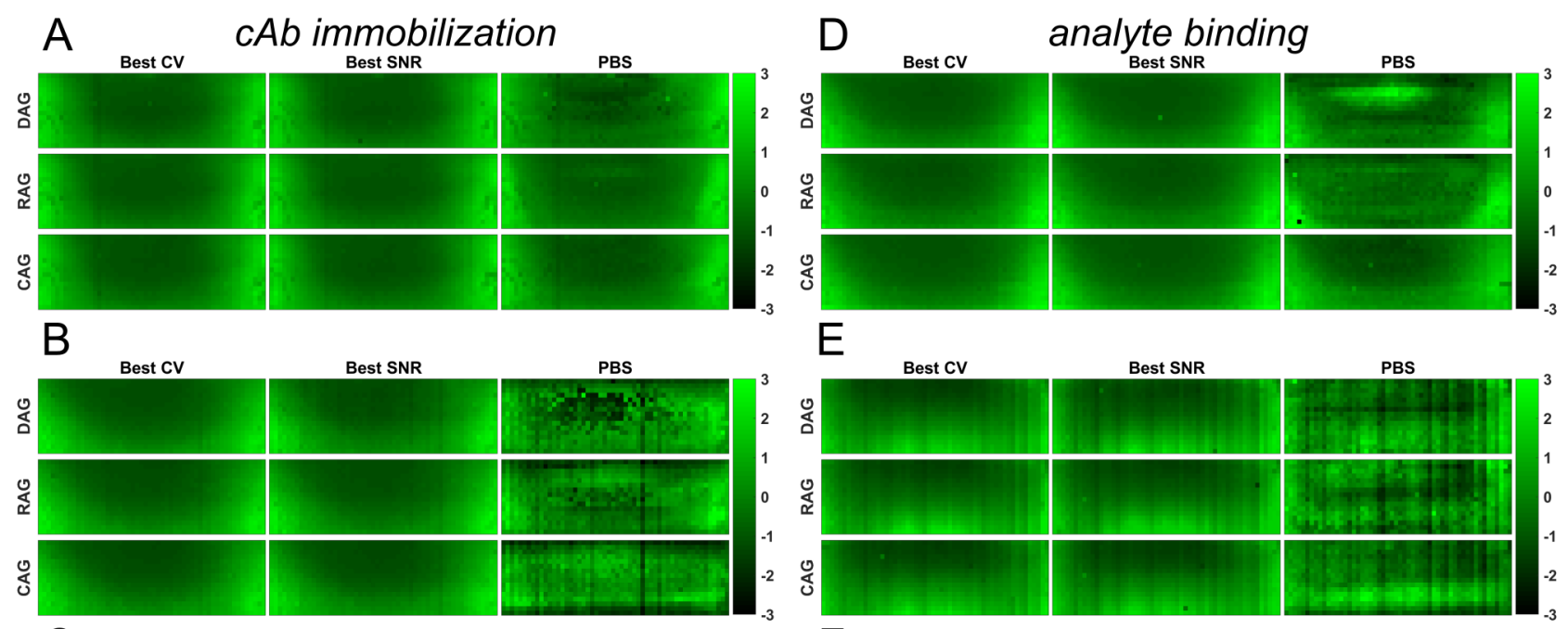

\section{E}
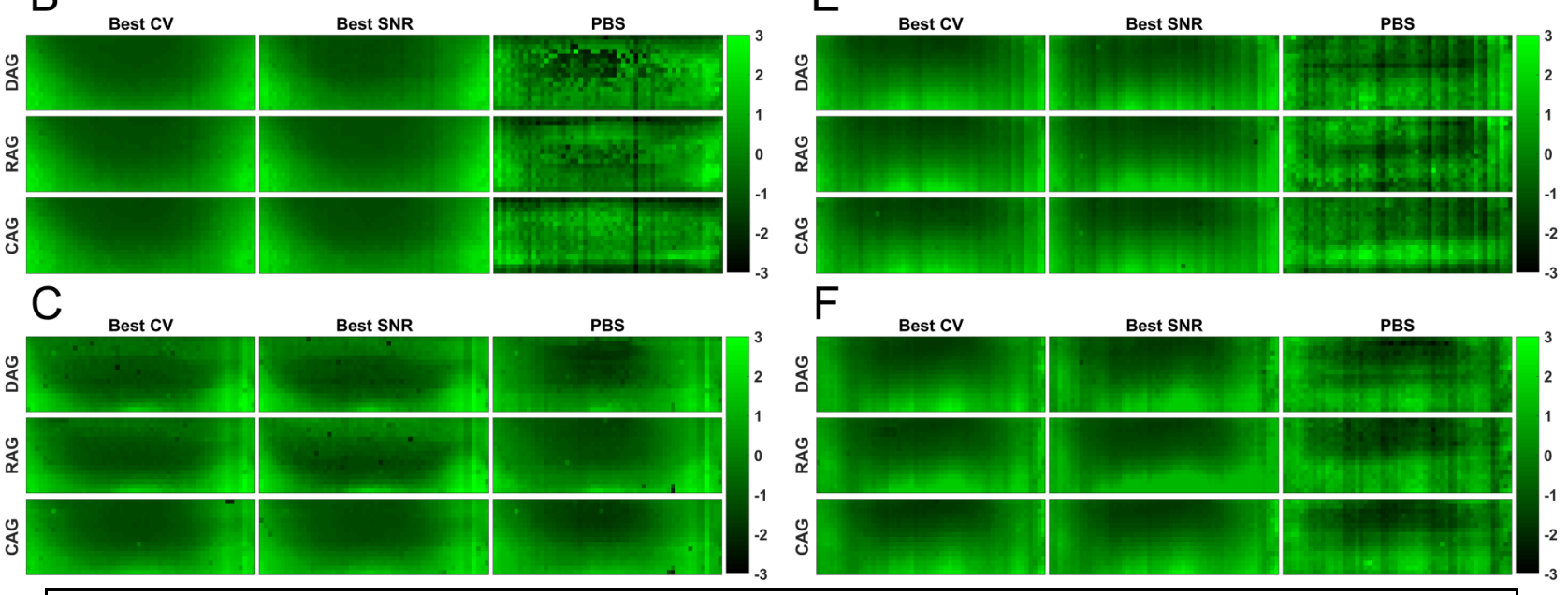

\begin{tabular}{|c|c|c|c|c|c|c|c|}
\hline \multicolumn{2}{|c|}{$G$} & \multicolumn{3}{|c|}{$c A b$ immobilization } & \multicolumn{3}{|c|}{ analyte binding } \\
\hline \multirow{4}{*}{ RS1 } & & Best CV & Best SNR & PBS & Best CV & Best SNR & PBS \\
\hline & DAG & $55.8 \%$ & $62.6 \%$ & $39.1 \%$ & $66.2 \%$ & $68.7 \%$ & $33.2 \%$ \\
\hline & RAG & $68.7 \%$ & $70.3 \%$ & $58.8 \%$ & $61.8 \%$ & $68.9 \%$ & $29.2 \%$ \\
\hline & CAG & $67.0 \%$ & $67.5 \%$ & $45.8 \%$ & $74.5 \%$ & $75.3 \%$ & $41.3 \%$ \\
\hline \multirow{3}{*}{ RS2 } & DAG & $65.4 \%$ & $39.8 \%$ & $14.3 \%$ & $43.3 \%$ & $30.8 \%$ & $13.9 \%$ \\
\hline & RAG & $57.3 \%$ & $54.3 \%$ & $12.7 \%$ & $40.6 \%$ & $39.3 \%$ & $12.3 \%$ \\
\hline & CAG & $57.6 \%$ & $56.4 \%$ & $9.6 \%$ & $41.9 \%$ & $36.9 \%$ & $15.4 \%$ \\
\hline \multirow{3}{*}{ RS3 } & DAG & $33.2 \%$ & $30.7 \%$ & $24.9 \%$ & $38.4 \%$ & $27.3 \%$ & $19.1 \%$ \\
\hline & RAG & $43.2 \%$ & $30.8 \%$ & $28.4 \%$ & $39.8 \%$ & $38.6 \%$ & $14.5 \%$ \\
\hline & CAG & $49.0 \%$ & $49.8 \%$ & $29.4 \%$ & $38.4 \%$ & $39.8 \%$ & $17.4 \%$ \\
\hline
\end{tabular}

$\begin{array}{llllllllllllllllllllllll}4 \% & 5 \% & 6 \% & 7 \% & 8 \% & 9 \% & 10 \% & 11 \% & 12 \% & 13 \% & 14 \% & 15 \% & 16 \% & 17 \% & 18 \% & 19 \% & 20 \% & 21 \% & 22 \% & 23 \% & 24 \% & 25 \%\end{array}$

Figure S6: Normalized, contrast enhanced fluorescent heatmaps in the 677-emission channel for the Slide E (SM4) slides revealing spatial variation and bias. Each panel demonstrates the nine heat maps for a single replicate slide. Each pixel represents the normalized fluorescence signal of a single spot after signal analysis and the color bar is centered on the whole slide mean (WSM) (0) and extends to \pm 3 standard deviation. Based on results in analyte binding, the best CV buffer is B22 and the best SNR buffer is B25 (see Fig. 1C). A-C. Heatmaps for the three replicate slides of capture antibody immobilization experiment. D-F. Heatmaps for the three replicate slides of the analyte binding antibody experiment. Different slides were used for capture antibody immobilization and analyte binding experiments. G. WSCV values (no background subtraction) for every individual heatmap. 


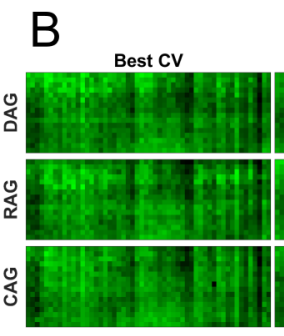

C

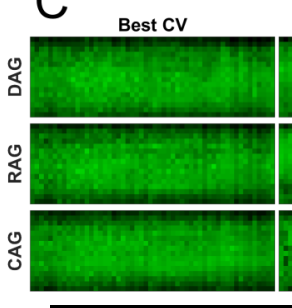

G

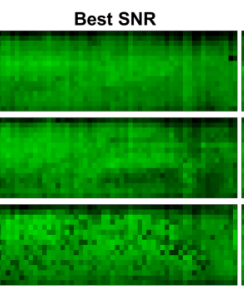

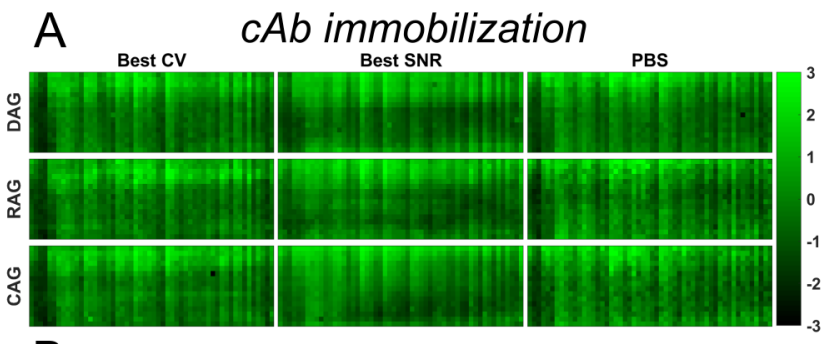

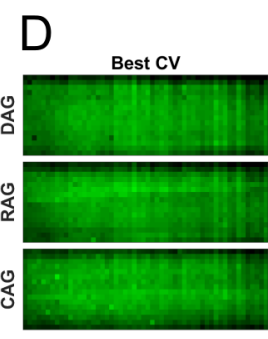

E

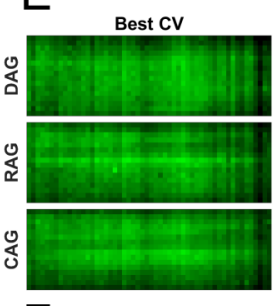

$\mathrm{F}$

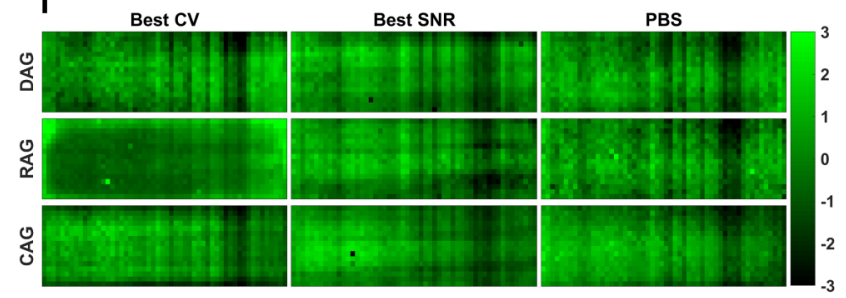

$c A b$ immobilization

PBS

$16.4 \%$

$14.5 \%$

$14.5 \%$

CAG

$16.7 \%$

$20.3 \%$

$11.1 \%$

RS2

DAG

\begin{tabular}{|c|c|c|}
\hline $10.2 \%$ & $12.8 \%$ & $11.1 \%$ \\
\hline $9.9 \%$ & $13.8 \%$ & $10.8 \%$ \\
\hline $9.5 \%$ & $11.7 \%$ & $10.8 \%$ \\
\hline
\end{tabular}

RS3

\begin{tabular}{|l|l|l|}
\hline $16.7 \%$ & $15.5 \%$ & $15.9 \%$ \\
\hline $16.8 \%$ & $19.9 \%$ & $16.0 \%$ \\
\hline $17.7 \%$ & $20.2 \%$ & $14.9 \%$ \\
\hline
\end{tabular}
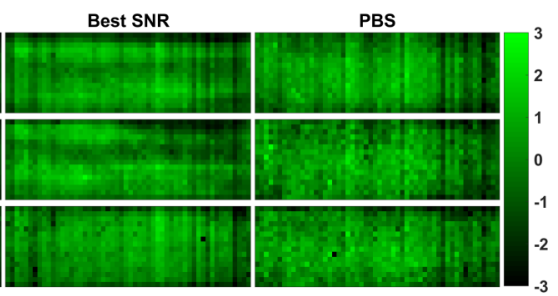

analyte binding

analyte binding

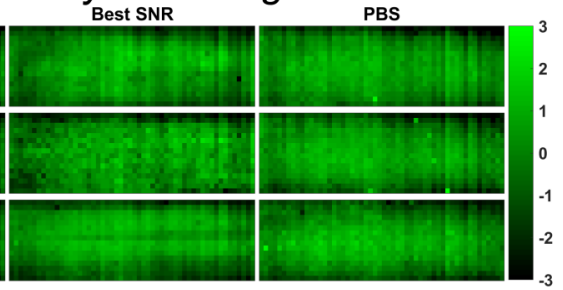

\begin{tabular}{|c|c|c|}
\multicolumn{1}{c}{ Best CV } & \multicolumn{1}{c}{ Best SNR } & PBS \\
\hline $13.4 \%$ & $14.0 \%$ & $12.4 \%$ \\
\hline $16.9 \%$ & $14.1 \%$ & $14.4 \%$ \\
\hline $18.6 \%$ & $17.7 \%$ & $18.2 \%$ \\
\hline
\end{tabular}

\begin{tabular}{|c|c|c|}
\hline $12.6 \%$ & $14.5 \%$ & $11.0 \%$ \\
\hline $14.9 \%$ & $19.9 \%$ & $12.9 \%$ \\
\hline $18.6 \%$ & $9.5 \%$ & $13.4 \%$ \\
\hline $12.4 \%$ & $11.3 \%$ & $12.4 \%$ \\
\hline $37.1 \%$ & $13.5 \%$ & $11.8 \%$ \\
\hline $16.2 \%$ & $18.6 \%$ & $18.2 \%$ \\
\hline
\end{tabular}

$\begin{array}{lllllllllllllllllllllll}4 \% & 5 \% & 6 \% & 7 \% & 8 \% & 9 \% & 10 \% & 11 \% & 12 \% & 13 \% & 14 \% & 15 \% & 16 \% & 17 \% & 18 \% & 19 \% & 20 \% & 21 \% & 22 \% & 23 \% & 24 \% & 25 \%\end{array}$

Figure S7. Normalized, contrast enhanced fluorescent heatmaps in the 677-emission channel for the Protein Microarray (SM5) slides revealing spatial variation and bias. Each panel demonstrates the nine heat maps for a single replicate slide. Each pixel represents the normalized fluorescence signal of a single spot after signal analysis and the color bar is centered on the whole slide mean (WSM) (0) and extends to \pm 3 standard deviation. Based on results in analyte binding, the best CV buffer is B24 and the best SNR buffer is B20 (see Fig. 1C). A-C. Heatmaps for the three replicate slides of capture antibody immobilization experiment. D-F. Heatmaps for the three replicate slides of the analyte binding antibody experiment. Different slides were used for capture antibody immobilization and analyte binding experiments. G. WSCV values (no background subtraction) for every individual heatmap. 

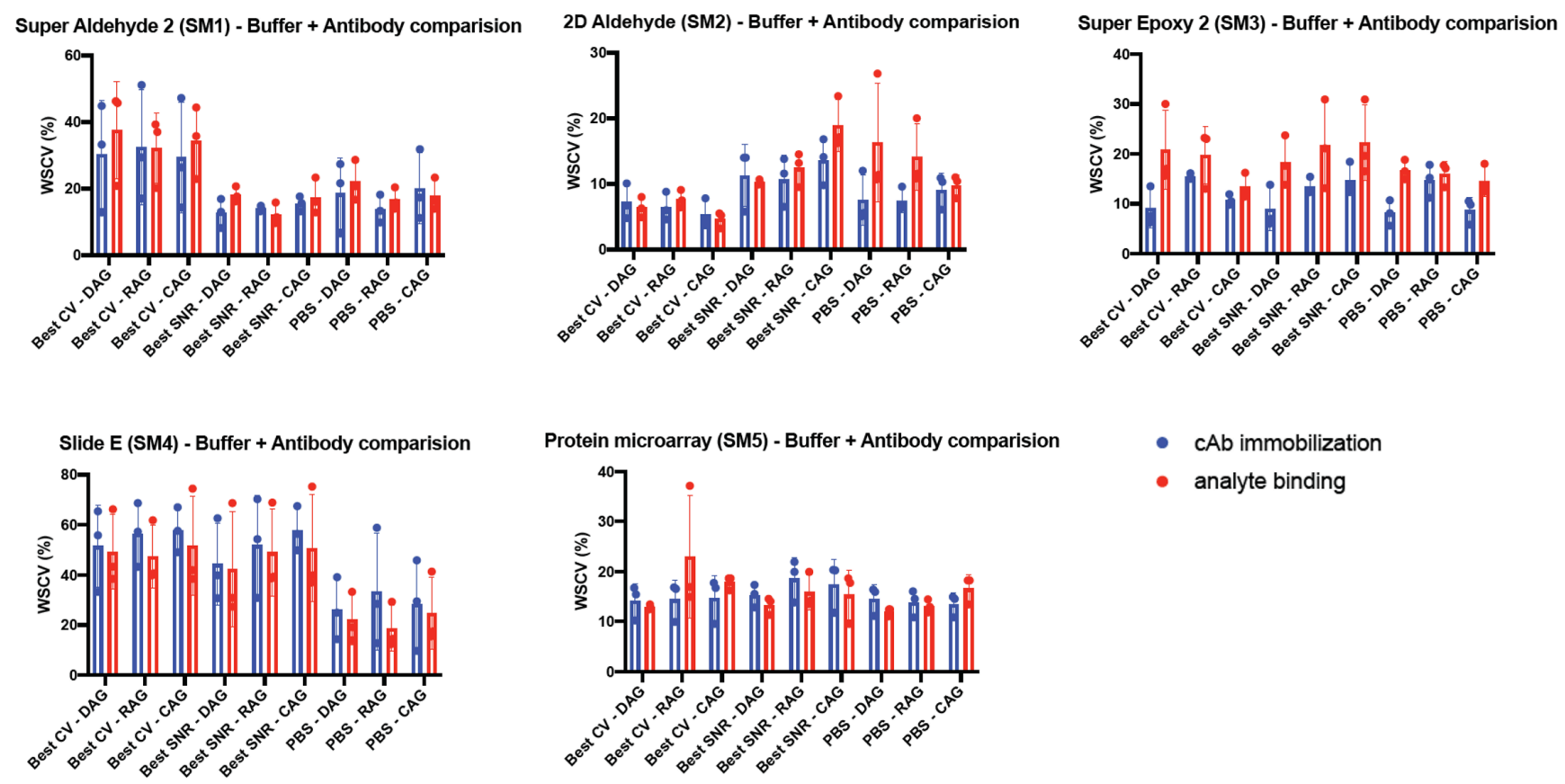

Figure S8. Comparison of the mean WSCV values for each SM generated from the triplicate cAb immobilization and analyte binding experiments (Fig. S3-7) for each SM-Buffer-antibody pairing. Multiple unpaired t tests with Welch correction (unequal variance $t$ tests) were performed using the built-in statistical analysis tool in GraphPad Prism (San Diego, CA, USA). An adjusted p-value <0.05 is set as the threshold for statistically significant difference. No statistically significant difference was identified between the WSCV of the $c$ Ab immobilization and analyte binding signal. 


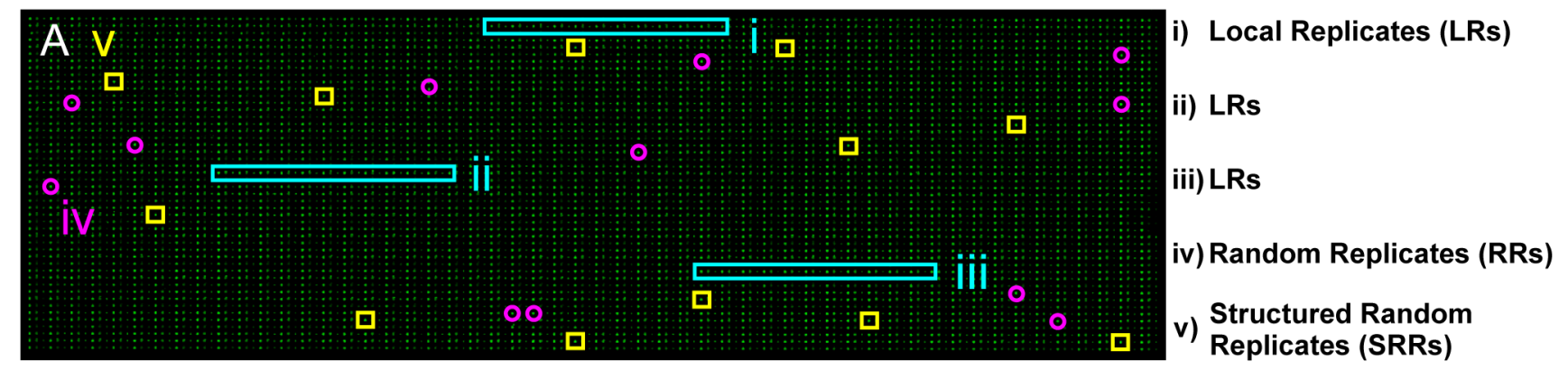

\begin{tabular}{|c|c|c|c|c|c|c|c|c|c|c|c|c|c|c|c|}
\hline \multirow{3}{*}{\multicolumn{2}{|c|}{$\begin{array}{l}\text { B } \\
\text { \# of } \\
\text { Replicates }\end{array}$}} & \multicolumn{6}{|c|}{ Slide E (SM4)-PBS-RAG } & \multicolumn{8}{|c|}{ Protein Microarray (SM5)-PBS-RAG } \\
\hline & & \multicolumn{2}{|c|}{ RS1 } & \multicolumn{2}{|c|}{ RS2 } & \multicolumn{2}{|c|}{ RS3 } & \multirow{2}{*}{$\begin{array}{l}\text { Inter- } \\
\text { slide } \\
\text { CV\% }\end{array}$} & \multicolumn{2}{|c|}{ RS1 } & \multicolumn{2}{|c|}{ RS2 } & \multicolumn{2}{|c|}{ RS3 } & \multirow{2}{*}{$\begin{array}{l}\text { Inter- } \\
\text { slide } \\
\text { CV\% }\end{array}$} \\
\hline & & $\begin{array}{l}\text { Signal } \\
\text { (RFU) }\end{array}$ & CV\% & $\begin{array}{l}\text { Signal } \\
\text { (RFU) }\end{array}$ & CV\% & $\begin{array}{l}\text { Signal } \\
\text { (RFU) }\end{array}$ & CV\% & & $\begin{array}{l}\text { Signal } \\
\text { (RFU) }\end{array}$ & CV\% & $\begin{array}{l}\text { Signal } \\
\text { (RFU) }\end{array}$ & CV\% & $\begin{array}{l}\text { Signal } \\
\text { (RFU) }\end{array}$ & CV\% & \\
\hline \multirow{3}{*}{ 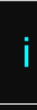 } & 4 & 12,621 & $4.8 \%$ & 16,007 & $8.3 \%$ & 21,774 & $4.9 \%$ & $27.5 \%$ & 16,329 & $8.4 \%$ & 24,930 & $14.0 \%$ & 16,920 & $3.7 \%$ & $24.8 \%$ \\
\hline & 6 & 11,983 & $7.1 \%$ & 15,802 & $9.0 \%$ & 21,765 & $4.0 \%$ & $29.9 \%$ & 15,350 & $10.9 \%$ & 23,856 & $11.8 \%$ & 16,218 & $10.6 \%$ & $25.3 \%$ \\
\hline & 12 & 12,499 & $9.1 \%$ & 15,935 & $8.1 \%$ & 21,592 & $4.7 \%$ & $27.5 \%$ & 14,441 & $14.0 \%$ & 24,273 & $13.1 \%$ & 16,454 & $10.2 \%$ & $28.2 \%$ \\
\hline \multirow{3}{*}{ ii } & 4 & 19,244 & $9.6 \%$ & 12,907 & $3.9 \%$ & 24,780 & $4.0 \%$ & $31.3 \%$ & 22,123 & $4.8 \%$ & 29,837 & $1.3 \%$ & 20,777 & $15.5 \%$ & $20.2 \%$ \\
\hline & 6 & 18,115 & $9.6 \%$ & 13,027 & $4.0 \%$ & 24,656 & $4.0 \%$ & $31.3 \%$ & 22,326 & $3.4 \%$ & 30,472 & $6.4 \%$ & 19,828 & $12.8 \%$ & $23.0 \%$ \\
\hline & 12 & 17,239 & $11.0 \%$ & 12,682 & $6.0 \%$ & 24,685 & $4.6 \%$ & $33.3 \%$ & 22,230 & $3.5 \%$ & 29,980 & $10.2 \%$ & 19,427 & $12.5 \%$ & $22.9 \%$ \\
\hline \multirow{3}{*}{ iii } & 4 & 18,773 & $4.6 \%$ & 15,423 & $8.4 \%$ & 30,535 & $3.7 \%$ & $36.8 \%$ & 19,324 & $4.4 \%$ & 28,634 & $6.4 \%$ & 18,610 & $4.1 \%$ & $25.2 \%$ \\
\hline & 6 & 19,036 & $4.1 \%$ & 15,225 & $8.4 \%$ & 30,896 & $6.7 \%$ & $37.6 \%$ & 19,518 & $7.5 \%$ & 26,797 & $10.4 \%$ & 17,111 & $10.1 \%$ & $23.9 \%$ \\
\hline & 12 & 21,453 & $19.2 \%$ & 15,458 & $7.6 \%$ & 31,784 & $6.7 \%$ & $36.1 \%$ & 19,599 & $6.6 \%$ & 26,637 & $10.5 \%$ & 17,334 & $10.4 \%$ & $22.9 \%$ \\
\hline \multirow{3}{*}{ iv } & 4 & 30,381 & $28.4 \%$ & 16,746 & $12.0 \%$ & 30,200 & $12.0 \%$ & $30.3 \%$ & 18,480 & $10.8 \%$ & 24,112 & $14.2 \%$ & 20,875 & $4.2 \%$ & $13.4 \%$ \\
\hline & 6 & 26,098 & $36.2 \%$ & 15,660 & $16.7 \%$ & 27,751 & $17.2 \%$ & $28.3 \%$ & 19,427 & $11.2 \%$ & 24,835 & $14.4 \%$ & 20,004 & $7.7 \%$ & $13.9 \%$ \\
\hline & 12 & 24,068 & $33.4 \%$ & 15,904 & $13.9 \%$ & 29,844 & $16.6 \%$ & $30.1 \%$ & 18,907 & $9.3 \%$ & 25,266 & $12.6 \%$ & 19,449 & $11.0 \%$ & $16.6 \%$ \\
\hline \multirow{3}{*}{ V } & 4 & 22,185 & $30.9 \%$ & 13,530 & $13.4 \%$ & 29,943 & $12.9 \%$ & $37.5 \%$ & 16,600 & $14.7 \%$ & 24,456 & $15.7 \%$ & 17,948 & $9.5 \%$ & $21.4 \%$ \\
\hline & 6 & 19,969 & $32.4 \%$ & 13,814 & $10.8 \%$ & 29,343 & $18.9 \%$ & $37.2 \%$ & 17,434 & $13.1 \%$ & 25,561 & $13.5 \%$ & 18,080 & $7.6 \%$ & $22.2 \%$ \\
\hline & 12 & 19,925 & $25.6 \%$ & 14,090 & $13.0 \%$ & 28,880 & $17.7 \%$ & $35.5 \%$ & 18,303 & $16.3 \%$ & 26,587 & $11.0 \%$ & 18,224 & $11.8 \%$ & $22.8 \%$ \\
\hline \multicolumn{2}{|c|}{$\begin{array}{l}\text { Whole- } \\
\text { Slide }\end{array}$} & 20,406 & $29.2 \%$ & 15,008 & $12.3 \%$ & 28,749 & $14.5 \%$ & $32.4 \%$ & 19,151 & $14.4 \%$ & 27,053 & $12.9 \%$ & 18,291 & $11.8 \%$ & $22.5 \%$ \\
\hline
\end{tabular}

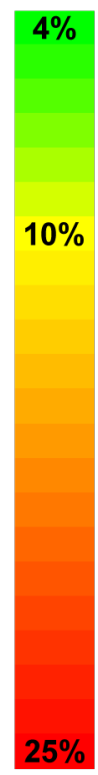

\begin{tabular}{|c|c|c|c|c|c|c|c|c|c|c|c|c|c|c|c|}
\hline \multirow{2}{*}{\multicolumn{2}{|c|}{$\begin{array}{l}\text { C } \\
\text { \# of } \\
\text { Replicates }\end{array}$}} & \multicolumn{6}{|c|}{ SuperAldehyde 2 (SM1)-PBS-RAG } & \multicolumn{8}{|c|}{ SuperEpoxy 2 (SM3)-PBS-RAG } \\
\hline & & $\begin{array}{r}\quad \mathbf{R} \\
\text { Signal } \\
\text { (RFU) }\end{array}$ & CV\% & $\begin{array}{l}\text { Rs } \\
\text { Signal } \\
\text { (RFU) }\end{array}$ & CV\% & \begin{tabular}{|r}
$\mathbf{R}$ \\
Signal \\
(RFU)
\end{tabular} & CV\% & $\begin{array}{l}\text { Inter- } \\
\text { slide } \\
\text { CV\% }\end{array}$ & $\begin{array}{r}\text { Rt } \\
\text { Signal } \\
\text { (RFU) }\end{array}$ & CV\% & $\begin{array}{r}\text { RS } \\
\text { Signal } \\
\text { (RFU) }\end{array}$ & CV\% & $\begin{array}{r}\mathbf{R} \\
\text { Signal } \\
\text { (RFU) }\end{array}$ & CV\% & $\begin{array}{l}\text { Inter- } \\
\text { slide } \\
\text { CV\% }\end{array}$ \\
\hline \multirow{3}{*}{ 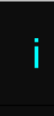 } & 4 & 13,858 & $3.7 \%$ & 20,826 & $5.6 \%$ & 19,170 & $9.9 \%$ & $20.3 \%$ & 11,792 & $2.9 \%$ & 12,360 & $9.2 \%$ & 5,138 & $19.2 \%$ & $41.1 \%$ \\
\hline & 6 & 13,729 & $3.5 \%$ & 19,467 & $9.2 \%$ & 19,027 & $6.9 \%$ & $18.3 \%$ & 11,183 & $7.3 \%$ & 11,641 & $11.2 \%$ & 5,697 & $18.1 \%$ & $34.8 \%$ \\
\hline & 12 & 13,706 & $3.8 \%$ & 19,059 & $8.3 \%$ & 18,247 & $9.3 \%$ & $17.0 \%$ & 11,178 & $6.5 \%$ & 11,170 & $12.6 \%$ & 5,557 & $16.7 \%$ & $34.9 \%$ \\
\hline \multirow{4}{*}{ ii } & 4 & 11,520 & $4.0 \%$ & 17,081 & $3.3 \%$ & 17,673 & $4.8 \%$ & $22.0 \%$ & 10,993 & $4.2 \%$ & 12,851 & $8.4 \%$ & 5,310 & $8.3 \%$ & $40.4 \%$ \\
\hline & 6 & 11,887 & $5.4 \%$ & 17,045 & $3.9 \%$ & 17,654 & $4.9 \%$ & $20.4 \%$ & 11,044 & $3.2 \%$ & 13,449 & $7.5 \%$ & 5,224 & $9.0 \%$ & $42.7 \%$ \\
\hline & 12 & 12,003 & $5.7 \%$ & 16,988 & $4.6 \%$ & 17,486 & $4.6 \%$ & $19.6 \%$ & 11,156 & $3.5 \%$ & 13,653 & $6.3 \%$ & 5,059 & $11.0 \%$ & $44.4 \%$ \\
\hline & 4 & 13,471 & $3.1 \%$ & 15,001 & $7.9 \%$ & 11,599 & $10.6 \%$ & $12.8 \%$ & 13,442 & $3.5 \%$ & 11,788 & $6.4 \%$ & 4,202 & $17.7 \%$ & $50.2 \%$ \\
\hline \multirow[t]{3}{*}{ iii } & 6 & 13,200 & $9.2 \%$ & 15,018 & $6.8 \%$ & 11,169 & $9.8 \%$ & $14.7 \%$ & 13,938 & $5.1 \%$ & 12,119 & $8.6 \%$ & 4,143 & $12.0 \%$ & $51.8 \%$ \\
\hline & 12 & 13,587 & $8.8 \%$ & 15,087 & $7.7 \%$ & 11,443 & $10.5 \%$ & $13.7 \%$ & 14,321 & $6.4 \%$ & 11,811 & $9.6 \%$ & 4,316 & $11.7 \%$ & $51.3 \%$ \\
\hline & 4 & 13,870 & $8.4 \%$ & 17,505 & $22.6 \%$ & 15,876 & $22.0 \%$ & $11.6 \%$ & 13,115 & $29.0 \%$ & 13,087 & $7.4 \%$ & 6,422 & $26.5 \%$ & $35.5 \%$ \\
\hline \multirow[t]{3}{*}{ iv } & 6 & 13,238 & $10.2 \%$ & 17,643 & $18.5 \%$ & 16,591 & $17.8 \%$ & $14.5 \%$ & 12,301 & $26.1 \%$ & 12,854 & $9.0 \%$ & 5,840 & $27.4 \%$ & $37.7 \%$ \\
\hline & 12 & 13,083 & $13.0 \%$ & 17,184 & $16.7 \%$ & 17,482 & $19.2 \%$ & $15.4 \%$ & 12,682 & $21.9 \%$ & 13,484 & $17.0 \%$ & 6,011 & $27.9 \%$ & $38.3 \%$ \\
\hline & 4 & 11,919 & $14.4 \%$ & 16,097 & $21.5 \%$ & 17,561 & $19.9 \%$ & $19.3 \%$ & 10,962 & $19.4 \%$ & 12,535 & $7.1 \%$ & 5,358 & $12.4 \%$ & $39.2 \%$ \\
\hline \multirow[t]{2}{*}{ V } & 6 & 12,143 & $11.4 \%$ & 16,592 & $17.6 \%$ & 17,067 & $19.3 \%$ & $17.8 \%$ & 11,502 & $16.7 \%$ & 12,562 & $5.9 \%$ & 5,106 & $12.8 \%$ & $41.5 \%$ \\
\hline & 12 & 12,261 & $11.6 \%$ & 16,377 & $13.9 \%$ & 16,464 & $17.6 \%$ & $16.0 \%$ & 12,065 & $17.8 \%$ & 12,693 & $7.6 \%$ & 4,965 & $17.5 \%$ & $43.3 \%$ \\
\hline \multicolumn{2}{|c|}{$\begin{array}{l}\text { Whole- } \\
\text { Slide }\end{array}$} & 12,174 & $15.8 \%$ & 16,988 & $13.9 \%$ & 15,970 & $20.4 \%$ & $16.9 \%$ & 12,105 & $17.1 \%$ & 12,524 & $13.3 \%$ & 5,054 & $17.7 \%$ & $42.4 \%$ \\
\hline
\end{tabular}

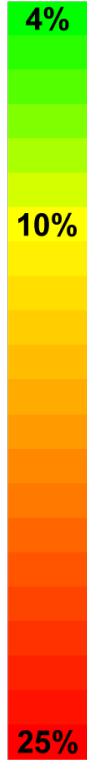

Figure S9. Illustration of how LRs can result in striking underestimation of variability while SRRs converge towards WSCV using identical analysis as shown in figure 3 of main text. A. Schematic of the locations for the 12-LRs (i-iii), RRs (iv), and SRRs (v). The 4 and 6 spot sets in i-v were a sub-selection of spots of the 12 shown in A. B. Summary of the mean and CV values for 4,6 , and 12 replicates used for replicate sets i-v on three replicate slides (RS1-RS3) for SM4-PBS-RAG and SM5-PBS-RAG from analyte binding experiments along with 'true' WSM and WSCV at the bottom and inter-slide CV to the right. C. Summary of the mean and CV values for 4, 6, and 12 replicates used for replicate sets i-v on three replicate slides (RS1-RS3) for SM1-PBS-RAG and SM3-PBS-RAG from analyte binding experiments along with 'true' WSM and WSCV at the bottom and inter-slide CV to the right. 


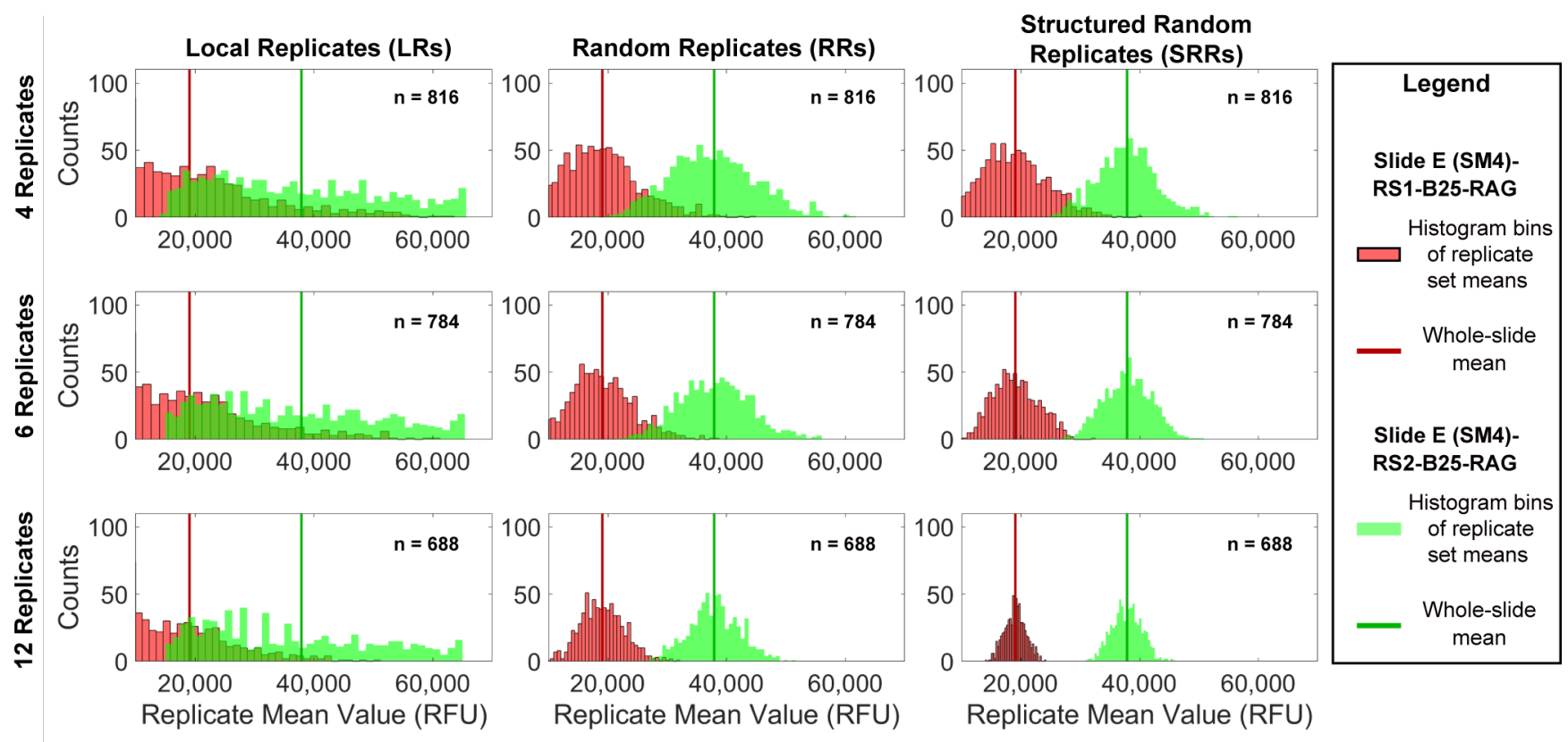

Figure S10. Systematic analysis of 4, 6, and 12 LRs, RRs, and SRRs for the SM4-RS1-B25-RAG and SM4-RS2-B25-RAG arrays illustrates LRs do not give normal distribution whereas RRs and SRRs do. A moving average for all possible LRs was used yielding different number of possible replicates $(n=816,784,688)$. Histogram of replicate spot set mean values for SM4-RS1-B25-RAG and SM4-RS2-B25-RAG arrays of analyte binding. 

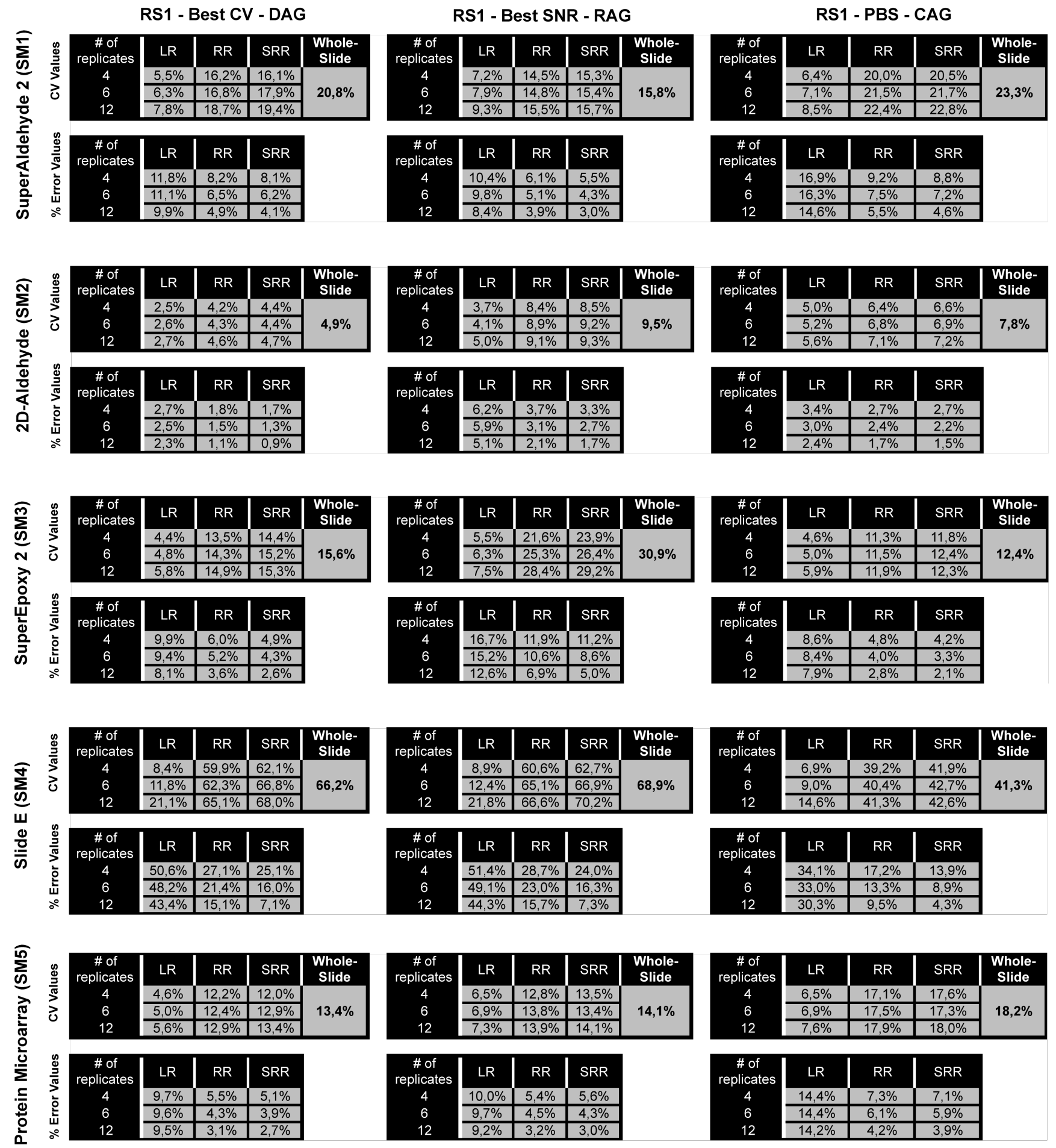

Figure S11. Systematic analysis of 4, 6, and 12 LRs, RRs, and SRRs for 15 arrays from analyte binding confirms that LRs were poor at estimating WSM and WSCV whereas SRRs gave the most accurate results for all slide models tested. 

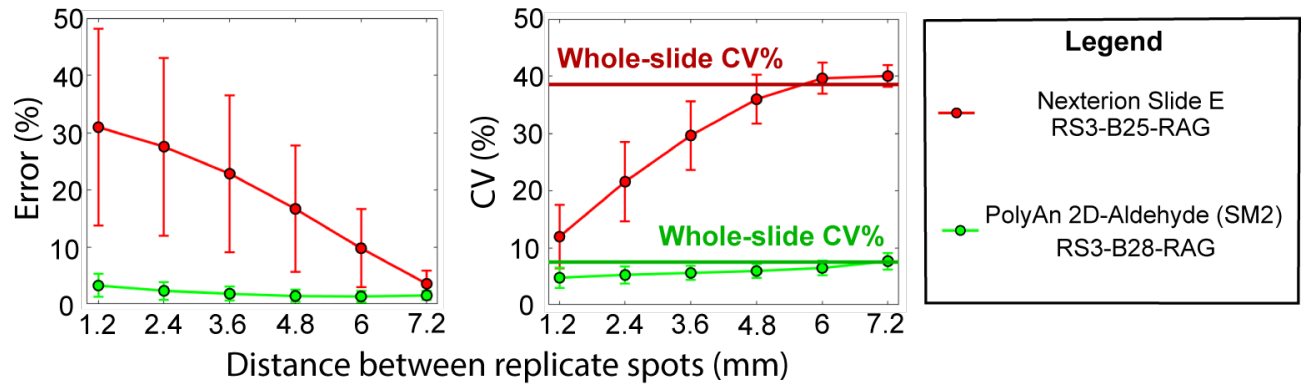

Figure S12. The mean and CV values of $3 \times 9$ grid of LR spots converges to the WSM and WSCV as the distance between replicates increases. Analyzing the SM4-RS3-B25-RAG and SM2-RS3-B28-RAG arrays from analyte binding, we used a replicate configuration of a $3 \times 9$ grid of LR spots $(1.2 \mathrm{~mm}$ pitch) and then formed 5 new replicate configurations by sequentially adding spacer spots in between spot replicates (2.4-7.2 mm pitch). A rolling average was then calculated for the 6 different replicate configurations. $\mathrm{n}=644$ for $1.2 \mathrm{~mm}$ pitch, 456 for $2.4 \mathrm{~mm}, 300$ for $3.6 \mathrm{~mm}, 176$ for $4.8 \mathrm{~mm}, 84$ for $6 \mathrm{~mm}$, and 24 for $7.2 \mathrm{~mm}$. 
A
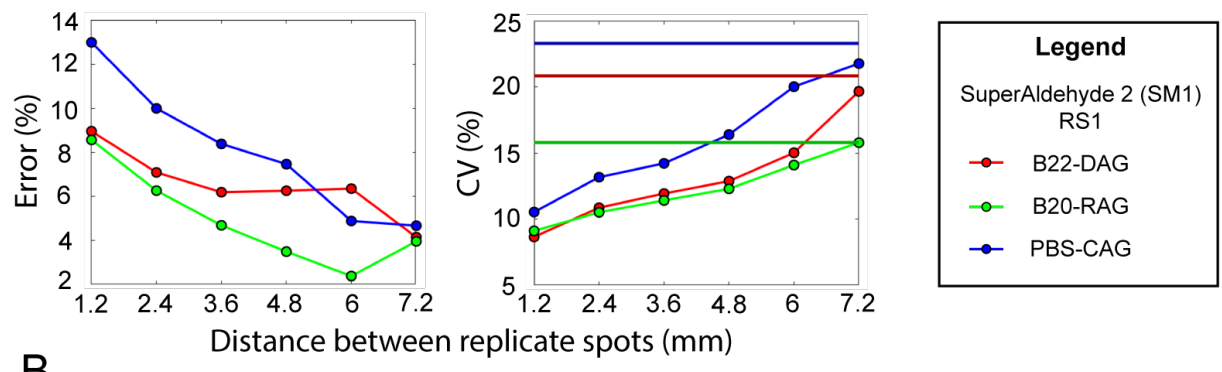

B
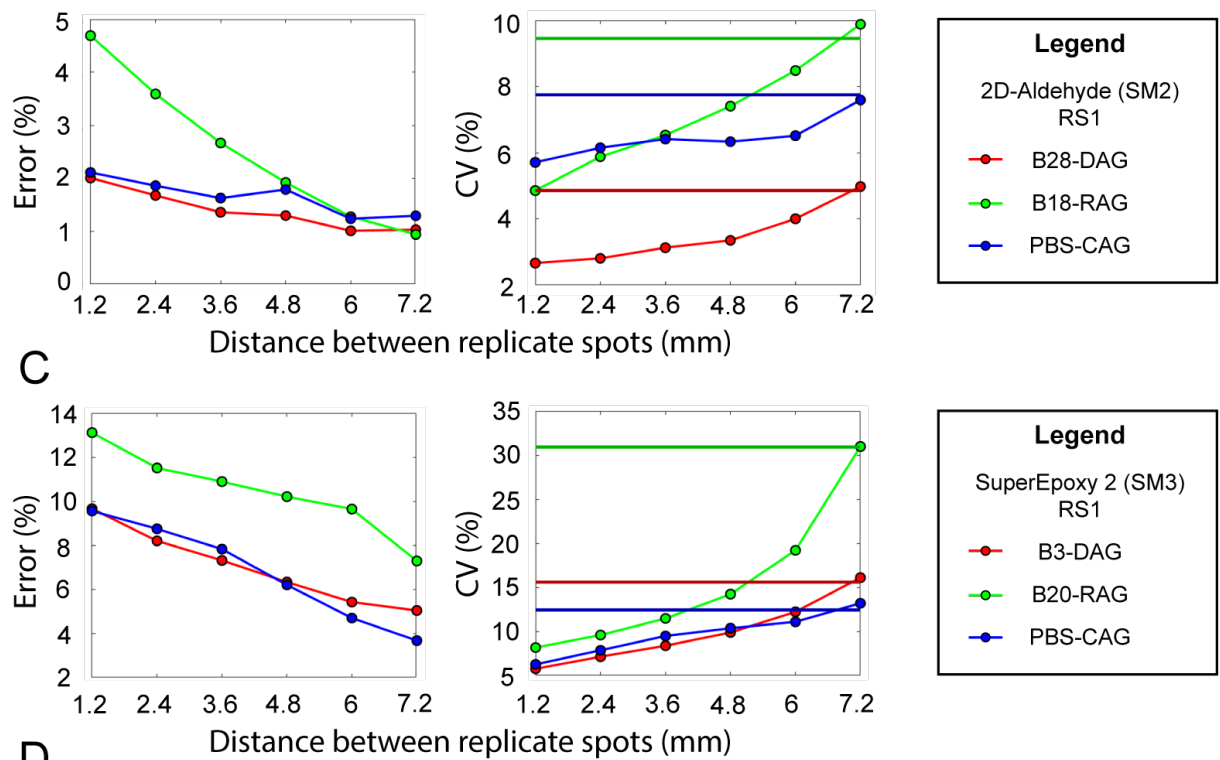

D

Distance between replicate spots $(\mathrm{mm})$
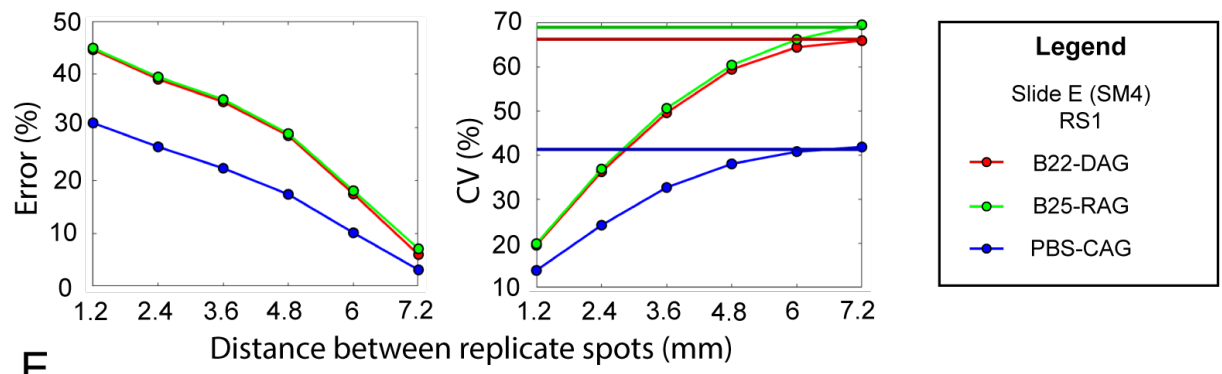

E

Distance between replicate spots $(\mathrm{mm})$
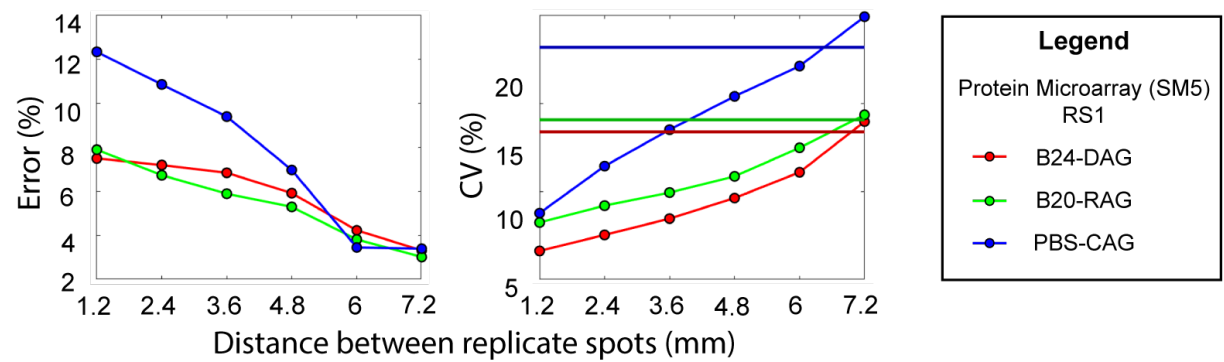

Figure S13. The mean and CV values of $3 \times 9$ grid of LR spots converges to the WSM and WSCV as the distance between replicates increases. Analyzing 3 arrays per SM (total of 15) from analyte binding, we used a replicate configuration of a $3 \times 9$ grid of LR spots (1.2 mm pitch) and then formed 5 new replicate configurations by sequentially adding spacer spots in between spot replicates (2.4$7.2 \mathrm{~mm}$ pitch). A moving average was then calculated for the 6 different replicate configurations. $\mathrm{n}=644$ for $1.2 \mathrm{~mm}$ pitch, 456 for $2.4 \mathrm{~mm}, 300$ for $3.6 \mathrm{~mm}, 176$ for $4.8 \mathrm{~mm}, 84$ for $6 \mathrm{~mm}$, and 24 for $7.2 \mathrm{~mm}$. Horizontal lines represent WSCV values for the corresponding array. 


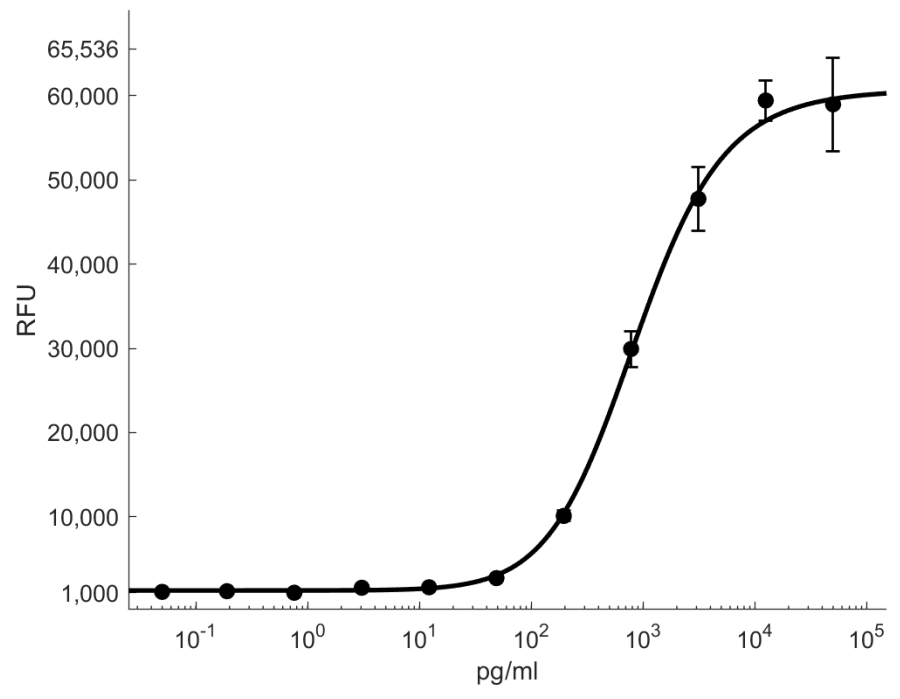

Figure S14. Binding curve for EGF sandwich assay in buffer. 